Document downloaded from:

http://hdl.handle.net/10251/88512

This paper must be cited as:

Cullin, J.; Spitler, JD.; Montagud Montalvá, Cl.; Ruiz Calvo, F.; Rees, S.; Naicker, S.; Konecny, P.... (2015). Validation of vertical ground heat exchanger design methodologies. Science and Technology for the Built Environment. 21(2):137-149. doi:10.1080/10789669.2014.974478

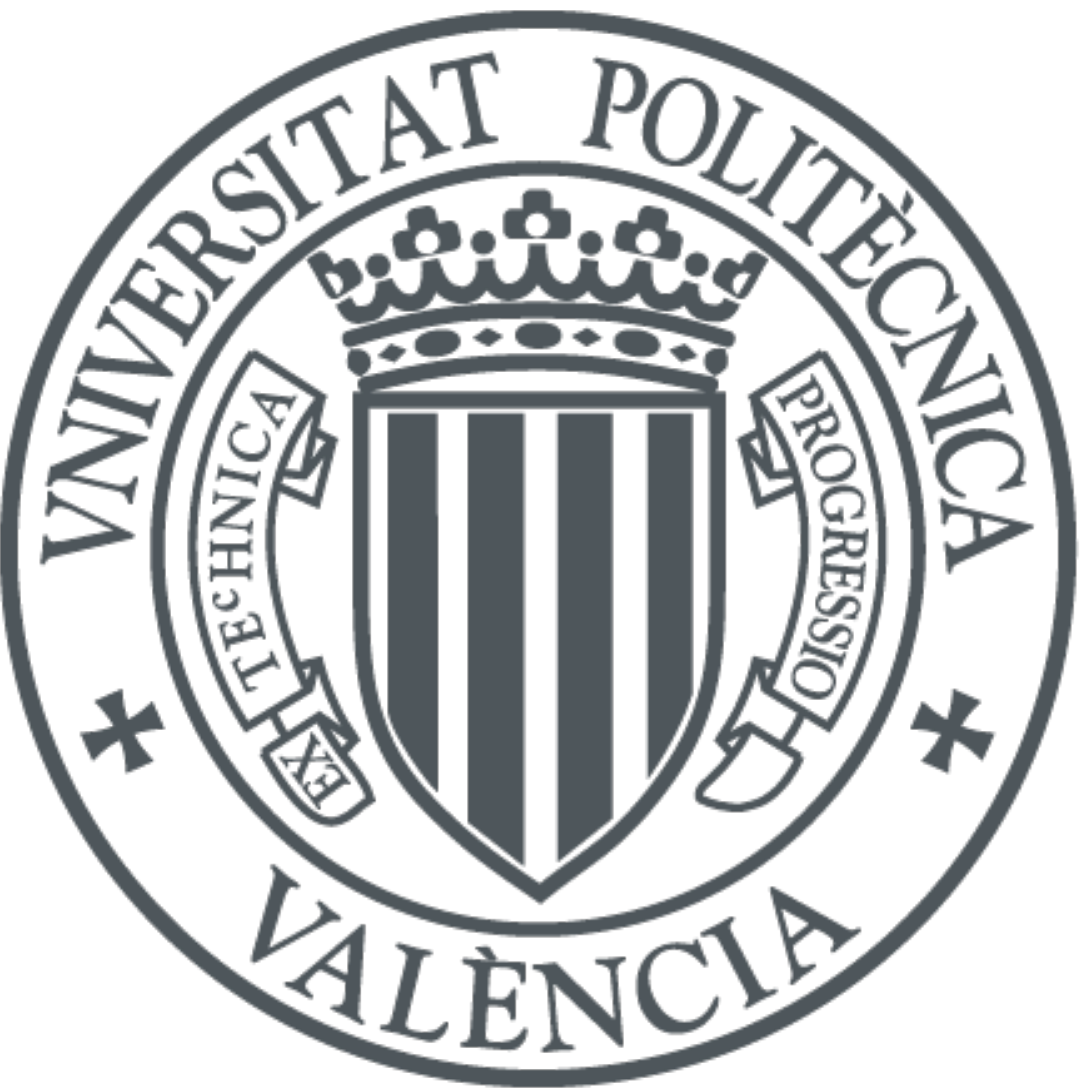

The final publication is available at

http://doi.org/10.1080/10789669.2014.974478

Copyright Taylor \& Francis

Additional Information 


\section{Validation of Vertical Ground Heat Exchanger Design Methodologies}

This work presents a validation of two common methods for designing vertical ground heat exchangers. Both a simulation-based design tool and the ASHRAE Handbook design equation are used to find design lengths for four different real systems, using actual experimental data, including building loads as well as physical parameters, as inputs. The measured minimum and maximum ground heat exchanger exiting fluid temperatures were used as the design constraint. The simulation-based design tool predicted the borehole length to within $6 \%$ in all cases, while the Handbook design equation yielded systems with errors from - $21 \%$ to 167\%. Most of this error can be explained by the way loads are represented in the Handbook equation, with differences in the borehole thermal resistance also playing a smaller part. The Handbook equation relies on a very simple load representation; though this allows it to be used as a simple hand calculation, it also precludes it achieving acceptable accuracy. It does not appear to be possible to revise the Handbook equation so as to both significantly improve its accuracy and allow its use in a simple hand calculation.

\section{Introduction}

Ground source heat pump (GSHP) systems are among the most efficient heating and cooling systems currently available (EPA, 2013). These systems utilize a ground heat exchanger (GHX) to extract heat from, and, in temperate climates, reject heat to the soil on a seasonal basis. In this manner, thermal energy is effectively stored in warm months for later usage during cooler months. Since GSHP systems are becoming more and more widely utilized, it is of extreme importance to have a reliable method for sizing the GHXs; additionally, any such method must be straightforward enough to achieve accurate results in a minimum of computation time.

At present, there are perhaps three types of methods for sizing the ground heat exchanger for a GSHP system design. The first method is to use some type of rule-of-thumb relating peak cooling capacity or peak heating capacity to a required depth. Particularly for non-residential systems, however, the ratio of capacity to depth varies widely (Underwood and Spitler, 2007; Spitler and Cullin, 2008). Therefore reduction of the sizing algorithm to a fixed borehole length per unit of peak capacity is unlikely to give satisfactory results, and the rule-of-thumb approach will not be further considered here.

The second type of method is based on computer simulation of the ground heat exchanger (Eskilson, 1987; Hellström et al., 1997; Spitler, 2000; Cullin and Spitler, 2011), whereby the necessary system parameters 
(borefield geometry, borehole completion, thermal properties, etc.) are used as inputs to a simulation tool that generates entering and exiting fluid temperatures as a function of time. These temperatures can then be compared to the desired temperature constraints - usually placed on the heat pump entering fluid temperatureand the GHX depth iteratively adjusted until those constraints are met, a process which is typically done automatically by the software. Many design and energy analysis tools (e.g., Hellström et al., 1997; Fisher et al., 2006; Liu and Hellström, 2006) rely on the g-function approach first developed by Eskilson (1987); one of these tools (Spitler, 2000) will be analyzed here. This tool, also described in some detail by Cullin (2008), is a ground heat exchanger simulation tool that operates on a hybrid time step - monthly average plus hourly peak, as described by Cullin and Spitler (2011) — and is widely used for system design due to its quick computations compared to other hourly simulation methods.

The other method for GHX system design, and the method currently presented by ASHRAE (2011), is that of Kavanaugh and Rafferty (1997). They give an equation derived from a cylinder-source model to compute a required heat exchanger length both for heating and for cooling (with the larger value, obviously, being the one required for the design). This method also utilizes tables of correction factors to adjust for both borehole-toborehole interference and thermal short-circuiting; however, the development of these factors is unclear, and other researchers (Bernier et al., 2008) have failed to reproduce the tabulated borehole resistances and shortcircuiting factors with any sort of accuracy. Others, however, have proposed alternative techniques for determination of the penalty value (Fossa, 2011; Capozza et al., 2012). This method has also been integrated into a software tool that automates much of the computation (Kavanaugh, 1995), and an enhanced version into a calculation spreadsheet (Philippe et al., 2010).

Shonder et al. (2000) performed a parallel testing of five commercial design programs for vertical ground heat exchangers, and found differences of $7 \%$ for a cooling-dominated site and $16 \%$ for a heating-dominated site. However, these results were for simulated buildings, and thus did not use experimental data. Additionally, while Kurevija et al. (2012) compared the resulting sizes of the Eskilson g-function method to the ASHRAE cylinder source-derived method for one building in Croatia, showing somewhat lower sizes produced by the ASHRAE method for a 30-year design, there has to date been no retrospective assessment of these methods using actual GHX data.

Finally, Staiti (2014) has performed a comparison of the ASHRAE method and the same simulation-based design tool utilized herein, for a variety of cases using both a residential building and an office in Italy. For these case studies, which used design (i.e., not actual monitored) data for the buildings as inputs, the ASHRAE 
method sizes the GHX by an average of $16 \%$ higher compared to the simulation-based method for a single Utube. For double U-tubes, the two methods produce roughly equivalent sizes, though this is due to an underprediction of the borehole thermal resistance in the ASHRAE method. While this work does show that the ASHRAE method may tend to produce different results from a simulation-based design method, there has still been no assessment of these methods against monitored data.

To assess the performance of both of these methods, they will be validated against data from several monitored GHX facilities, as described in the next section. Traditional validation efforts typically involve using a simulation to determine fluid temperatures, which are then checked against experimental values. However, for this work, the design tools are used to size the GHX for the system, with the measured peak heat pump entering fluid temperatures serving as the design constraints. This approach provides insight into the accuracy of the ground heat exchanger sizes computed by the two commonly-used design approaches.

To check the suitability of the equation-based method, relevant information including total and peak load values, as well as maximum temperatures, will be entered into the design equation. The resulting "design length" is then compared to the actual installed GHX length, to see how well the equation predicts GHX length requirements. This value can also be compared to the length obtained with the simulation-based design tool, so that the relative performance of the two techniques can be assessed.

It may be the case that the ASHRAE Handbook design equation was intended to use concepts such as block loads and equivalent full-load hours in its sizing of GHXs, and that the method is designed to produce a "worst case" estimate if the design month, and peak block load, were to follow a prolonged annual load imbalance. In practice, this is not likely to be the case, as the ground temperature will experience some seasonal rise and fall. In any case, utilizing hourly measured data represents the best possible way to compare the performance of this method to other design techniques, such as that used by the simulation-based design tool. Thus, while a direct comparison of the two methodologies as performed herein may not be perfect due to the respective developments of those two methods, it remains the most feasible option for analyzing the relative performance of these methods.

\section{Measured Data}

Yavuzturk and Spitler (2001) identified criteria for field tests that would be ideal for use in experimental validation of ground heat exchanger simulations: (1) independent measurement of ground thermal properties (2) carefully calibrated and monitored data acquisition including, at least, measurement of entering and exiting fluid temperatures and flow rates (3) continuous data collection from the beginning of the ground heat 
exchanger operation, and (4) well characterized borehole geometry, backfill material properties, and heat transfer fluid properties. These same criteria apply for validation of ground heat exchanger design methods. To these criteria, we might also add that it is desirable to have multiple years of continuous data - the more the better - and, if possible, it would also be ideal to have a range of system sizes and climates as well as a range of system parameters such as number of boreholes, borehole spacing, borehole depths, backfill materials, etc. Such data sets have been in remarkably short supply.

This paper brings together results from four different GSHP facilities, selected to meet the above criteria as closely as possible. Two are located in the United States: one is an experimental facility in Stillwater, OK, and the other is at the ASHRAE Headquarters in Atlanta, GA. The remaining two are in Europe: one in Valencia, Spain, and one in Leicester, United Kingdom. For each system, there will be by design some "inactive" length at the top of each borehole, where the U-tube connects to the manifold piping. Cullin and Spitler (2013) explored the effect of any present horizontal piping on the performance of a vertical GHX, and found that it could be accounted for as an "effective" length of vertical piping. For the purposes of this work, then, a corresponding equivalent length of connecting horizontal piping is considered, so that the actual active length is equal to the installed vertical design length. This is done in absence of any knowledge of the inactive and horizontal piping portions of the four GHXs, so that these two secondary effects cancel each other out. As designers typically neglect both these secondary effects, this mirrors what is done by designers. Each system will now be discussed in detail.

Stillwater, OK. Hern (2002) designed and constructed a hybrid ground source heat pump test facility at Oklahoma State University in Stillwater OK. The ground heat exchanger consists of three vertical boreholes, each $114 \mathrm{~mm}(4.5 \mathrm{in})$ in diameter and averaging about $75 \mathrm{~m}(246 \mathrm{ft})$ in length, spaced $6 \mathrm{~m}(20 \mathrm{ft})$ apart and connected in parallel. The cooling capacity of the ground loop is supplemented by a three-ton evaporative cooling tower, connected to the loop via a plate heat exchanger in order to maintain a closed-loop system. Two water-to-water heat pumps with a nominal cooling capacity of $11 \mathrm{~kW}$ (3 tons) are used in the facility; one is configured to operate in cooling mode, while the other operates only in heating mode. For the majority of the experiment, only one heat pump is in operation; later in the experiment, the two are run simultaneously for a short time.

Hern (2002) measured the thermal properties in each borehole, finding a narrow range of values for each parameter. On average, the conductivity of the soil around the boreholes was $2.55 \mathrm{~W} / \mathrm{m}-\mathrm{K}\left(1.473 \mathrm{Btu} / \mathrm{hr}-\mathrm{ft}-{ }^{\circ} \mathrm{F}\right)$, with an average borehole thermal resistance of $0.162 \mathrm{~m}-\mathrm{K} / \mathrm{W}\left(0.280 \mathrm{hr}-\mathrm{ft}-{ }^{\circ} \mathrm{F} / \mathrm{Btu}\right)$; the mean undisturbed ground 
temperature for the three boreholes was $17.3^{\circ} \mathrm{C}\left(63.1^{\circ} \mathrm{F}\right)$. A sensitivity analysis performed by Hern (2002) showed that a soil heat capacity of $2.0 \times 10^{6} \mathrm{~J} / \mathrm{m}^{3}-\mathrm{K}\left(30 \mathrm{Btu} / \mathrm{ft}^{3}-{ }^{\circ} \mathrm{F}\right)$ produced adequate, and conservative, simulation results for this system; in the lack of heat capacity data for the other three systems, this value is assumed everywhere. The fluid flow rate, for times when the system was on and operational, was roughly 0.63 L/s (10 GPM). The system was instrumented with flow meters and thermocouples at many locations within the system, including at both the inlet and outlet of each borehole. Data were recorded at one minute intervals for the eighteen-month period from March 2005 through August 2006, and then automatically post-processed into averages of 10-minute duration. The experiment was run continuously except for very brief periods of computer downtime and regular system maintenance. Figure 1 below shows the heat pump entering and exiting (or the GHX exiting and entering) fluid temperatures for the first 12 months of operation, plotted as daily averages, while Figure 2 shows the total heat extracted from the ground on a daily basis, in $\mathrm{kWh} /$ day. These loads were computed based on the measured temperature difference across the three boreholes in operation. There are two distinct splits in the data, one in late March and the other at the end of November, which coincide with the transition between heating and cooling modes. Times with zero load, such as early December and parts of February, are incidents with no data, meaning the system was temporarily down for computer upkeep or routine system maintenance. Additionally, since the ground loads were computed based on the system flow rate and the temperature difference across the ground heat exchanger, regardless of whether the heat pump was actually in operation, there are some hours with a "heating" load during cooling season or a "cooling" load in heating season. These are preserved in the data to allow for a complete description of the ground thermal behavior.

For validation purposes, the first year of data was utilized since the maximum loop temperatures were encountered during this period. Exploration with the simulation-based design tool showed that, even if the entire 19 months were utilized, the resulting design length is equivalent. Therefore, a single year design period was selected for both the simulation-based design tool as well as the Handbook design equation.

Valencia, Spain. In 2005, the Universitat Politècnica de València installed a 6-borehole ground heat exchanger system as part of their research in energy-efficient buildings (Montagud et al., 2011). Specifically, the system was designed to facilitate comparison of an actual ground-source heat pump system to a standard airsource system. The Valencia system consists of six boreholes, each $50 \mathrm{~m}$ (164ft) deep, in a 2x3 rectangular formation spaced $3 \mathrm{~m}(10 \mathrm{ft})$ apart. The boreholes were backfilled with the same type of soil surrounding the borefield, which possessed a measured conductivity of $1.6 \mathrm{~W} / \mathrm{m}-\mathrm{K}\left(0.92 \mathrm{Btu} / \mathrm{hr}-\mathrm{ft}-{ }^{\circ} \mathrm{F}\right)$. With its location near 
the Mediterranean coast of Spain, the undisturbed ground temperature at the site is $19.5^{\circ} \mathrm{C}\left(67.1^{\circ} \mathrm{F}\right)$. The nominal system flow rate is $0.76 \mathrm{~L} / \mathrm{s}(12 \mathrm{GPM})$, or about $0.13 \mathrm{~L} / \mathrm{s}(2 \mathrm{GPM})$ per borehole, as there are six boreholes connected in parallel.

For this system, temperatures were measured at both the inlet and outlet of each borehole, as well as the heat pump, at sixty-second increments for six years of weekday daytime operation. The flow rate going out to the borefield and the power consumption of both heat pump and circulating pump were also measured. Figure 3 shows the heat exchanger inlet and outlet temperatures for 2010, the sixth full year of operation, averaged to give daily values. Figure 4 shows the total heat extracted from the ground on a daily basis, in $\mathrm{kWh}$ (or kBtu) per day. The system operates in heating mode from January through April, and again from late October until the end of the year. In this analysis, the first three years of operation are stop-and-start, with 15 of the 36 months, including eight consecutive, not running or recording data.

As described in Cullin et al. (2014), only the final three years of data, when the system is in continuous operation and shows a typical cyclical load profile, are used in this analysis. This was done because the system experienced stop-and-start operation over the first three years, including a span of 16 months during which only two months featured any actual operation. So, for the purposes of validating the design procedures, the average of years 4-6, when the system operated under conditions approaching steady periodic (i.e., the condition typically assumed for designing a VGHX), were utilized. As a result, three years was chosen as the system duration for sizing the GHX. Subsequent testing with a six years of design period (but still using the same cyclic load profile from years 4-6 as before) gave only a $1 \%$ increase in the size of the GHX when sized by the SBDT , and only a 3\% increase when sized by the design equation.

Atlanta, GA. The ASHRAE Headquarters building in Atlanta, GA (Parsons, 2008) is an office building with a floor area of around $3250 \mathrm{~m}^{2}\left(35,000 \mathrm{ft}^{2}\right)$, with the heating and cooling for the second floor only provided by a ground source heat pump system. The ground heat exchanger for this system utilizes 12 boreholes each $122 \mathrm{~m}$ (400ft) in depth, oriented in a 2x6 rectangular field and spaced $7.6 \mathrm{~m}(25 \mathrm{ft})$ apart. An in situ thermal conductivity test was performed on a test borehole, indicating a thermal conductivity of $3.25 \mathrm{~W} / \mathrm{m}-\mathrm{K}(1.88$

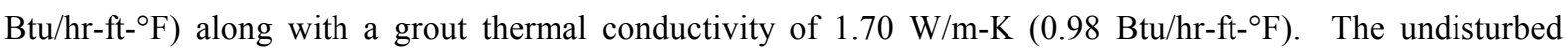
ground temperature was determined from this test to be $20.2^{\circ} \mathrm{C}\left(68.4^{\circ} \mathrm{F}\right)$. The design system flow rate is approximately $9.5 \mathrm{~L} / \mathrm{s}(150 \mathrm{GPM})$ of water, though actual measured flow rates do vary.

The GHX system is monitored to provide experimental measurements of flow rate as well as entering and exiting fluid temperatures every 15 minutes. As with the other systems, Figures 5 and 6 below show the 
average daily heat pump entering and exiting fluid temperatures, as well as the daily heat extracted from the ground, for the first twelve months of monitored operation beginning in March 2010; data through the end of 2012 was used for this analysis. The gaps in September and November are periods when the system was not operational, or no data were reported.

This system was actually operational for 21 months prior to March 2010. However, changes in the data acquisition system resulted in data prior to March 2010 being lost. To investigate the best method to account for this lost data, a simple load prediction scheme was created to retrospectively "forecast" the loads on the system prior to commencement of monitoring. The past loads on the ground heat exchanger were predicted based on average daily air temperature, which is available from weather data for Atlanta. For the existing data, a cubic curve fit was created to fit the daily GHX load to the daily average air temperature. Thus, loads for the time before monitoring began were computed based on the air temperature for those days and the calculated curve fit. Figure 7 shows the monthly net heat rejection, both as estimated from the curve-fitting procedure and-once data measurement began - as measured. As Figure 7 shows, there is some year-to-year variation in the estimated loads, on the order of $10 \%$. However, there is no evidence to suggest any long-term shift in the overall load pattern. Therefore, when validating the design procedures, the average of the three full years of actual measured data was used. The peak loads used in the design procedures were the absolute highest loads from the latest year of data, as they corresponded to the maximum measured temperature. For the design period, however, since the system has been in operation for a total of five years, five years was chosen as the design period for both the simulation-based design tool and Handbook design equation to determine the required GHX length based on the experimental data.

Leicester, United Kingdom. Researchers at De Montfort University in Leicester, United Kingdom, have carried out intensive monitoring of a large-scale non-domestic GSHP system to provide data for performance evaluation, control strategy assessment, and model validation (Naicker and Rees, 2011). The GHX consists of 56 boreholes, each $100 \mathrm{~m}$ (328ft) deep; the borefield is split into two arrays with 37 below the building's courtyard and the remaining 19 outside the building. Thermal conductivity testing gave an average value of 3.2 $\mathrm{W} / \mathrm{m}-\mathrm{K}\left(1.85 \mathrm{Btu} / \mathrm{hr}^{-\mathrm{ft}-}{ }^{\circ} \mathrm{F}\right)$, with a specified grout thermal conductivity of $2.0 \mathrm{~W} / \mathrm{m}-\mathrm{K}\left(1.16 \mathrm{Btu} / \mathrm{hr}-\mathrm{ft}-{ }^{\circ} \mathrm{F}\right)$; this grout value is a weighted average representative of the entire borehole, as only the top $25 \%$ of each borehole was grouted, with the rest being backfilled by cuttings produced during the drilling process. The borefield is served by a variable speed pump with a maximum flow rate of $30 \mathrm{~L} / \mathrm{s}$ ( $476 \mathrm{GPM})$; the operating fluid is a $20 \%$ propylene glycol mixture. 
Operation and monitoring of the system began in December 2009. However, measurements of system flow rate were not available until March 2010. For those first months, then, flow data were derived from correlations of temperature data established using complete data from later months. Figures 8 and 9 below show the heat pump entering and exiting fluid temperatures, as well as the daily heat rejected to the ground (negative numbers indicate rejection), for the first year of operation; 24 months of data were used in the analysis, and a design period of two years was selected for both design methodologies. The system provides part of the building's heating demand and all of the cooling demand. The load is cooling dominated overall but loads are less than anticipated at the design stage and so year-on-year increases in ground temperature have been modest - as have peak fluid temperatures.

\section{Methodology}

This work compares the design lengths generated from the ASHRAE Handbook design equationspecifically, the detailed method published by Kavanaugh and Rafferty (1997) - to design lengths from a validated simulation-based design tool. Specifically, the data and physical parameters from the experimental facilities presented in the previous section are used as inputs for both methods, so that the resulting design lengths can also be assessed with respect to the actual installed GHX length from the real installations. Following is a detailed overview of both the simulation-based design tool and the ASHRAE Handbook method, including how the data and parameters from the experiment are used in each.

Simulation-Based Design Tool. The monthly design tool used for this analysis utilizes Eskilson's gfunctions (1987) as its basis. For a single borehole, Eskilson computed the temperature response around the borehole due to a step change in heat input, using a two-dimensional finite difference method in radial-axial coordinates. By superimposing solutions for multiple boreholes, a non-dimensional response termed the "gfunction" can be created that represents the thermal behavior of a specific ground heat exchanger as a function of time and heat input. The temperature at the borehole wall at the end of an arbitrary month $n$ is then:

$$
T_{\text {borehole }}=\sum_{i=1}^{n} \frac{\left(Q_{i}-Q_{i-1}\right)}{2 \pi k} g\left(\frac{t_{i}}{t_{s}}, \frac{r_{B}}{H}\right)+T_{U G}
$$

Where:

$T_{\text {borehole }}$ is the borehole wall temperature $\left[{ }^{\circ} \mathrm{C}\right.$ or $\left.{ }^{\circ} \mathrm{F}\right]$;

$Q_{i}$ is the heat injection rate per unit length of pipe $[\mathrm{W} / \mathrm{m}$ or Btu/hr-ft];

$n$ is the current time of interest [s]; 
$k$ is the ground thermal conductivity $\left[\mathrm{W} / \mathrm{m}-\mathrm{K}\right.$ or $\left.\mathrm{Btu} / \mathrm{hr}-\mathrm{ft}-{ }^{\circ} \mathrm{F}\right]$;

$g$ is the value of the g-function at the specified point [-];

$t_{i}$ is the time at the $i^{\text {th }}$ time step [s];

$t_{s}$ is the time scale $[\mathrm{s}]$;

$r_{b}$ is the borehole radius [m or $\left.\mathrm{ft}\right]$;

$H$ is the depth of the borehole [m or $\mathrm{ft}]$; and

$T_{U G}$ is the undisturbed ground temperature $\left[{ }^{\circ} \mathrm{C}\right.$ or $\left.{ }^{\circ} \mathrm{F}\right]$.

The fluid temperature in the borehole, then, is based on the borehole wall temperature and thermal resistance:

$$
T_{f}=T_{\text {borehole }}+R_{b} \cdot Q_{i}
$$

Where:

$T_{f}$ is the temperature of the working fluid $\left[{ }^{\circ} \mathrm{C}\right.$ or $\left.{ }^{\circ} \mathrm{F}\right]$;

$R_{b}$ is the borehole thermal resistance $\left[\mathrm{K} /(\mathrm{W} / \mathrm{m})\right.$ or $\left.{ }^{\circ} \mathrm{F} /(\mathrm{Btu} / \mathrm{hr}-\mathrm{ft})\right]$; and

$Q_{i}$ is the heat injection rate per unit length of pipe $[\mathrm{W} / \mathrm{m}$ or Btu/hr-ft].

The borehole thermal resistance may be inferred from experimental values, or it can be computed analytically using an approach like the multipole method (Bennet et al., 1987; Claesson and Hellström, 2011). Finally, the heat pump entering and exiting fluid temperatures are calculated by assuming that the temperature change between inlet and exit is linear. Thus, the heat pump entering fluid temperature is computed as

$$
T_{i n}=T_{f}-\frac{Q_{i} \cdot H \cdot N B}{2 \cdot \dot{m} \cdot c_{p}}
$$

while the heat pump exiting fluid temperature is determined by

$$
T_{\text {out }}=T_{f}+\frac{Q_{i} \cdot H \cdot N B}{2 \cdot \dot{m} \cdot c_{p}}
$$

Where:

$T_{\text {in }}$ is the heat pump entering fluid temperature $\left[{ }^{\circ} \mathrm{C}\right.$ or $\left.{ }^{\circ} \mathrm{F}\right]$;

$T_{\text {out }}$ is the heat pump exiting fluid temperature $\left[{ }^{\circ} \mathrm{C}\right.$ or $\left.{ }^{\circ} \mathrm{F}\right]$;

$N B$ is the number of boreholes in the system [-];

$\dot{m}$ is the mass flow rate of the working fluid $[\mathrm{kg} / \mathrm{s}$ or $1 \mathrm{bm} / \mathrm{s}]$;

$C_{p}$ is the specific heat of the working fluid $\left[\mathrm{J} / \mathrm{kg}-\mathrm{K}\right.$ or $\left.\mathrm{Btu} / \mathrm{lbm}-^{\circ} \mathrm{F}\right]$; and

other quantities are as described in Equations 1 and 2. 
To determine a design length, the tool uses an initial guess and runs the monthly simulation. This produces a minimum and a maximum peak heat pump entering fluid temperature (EFT), which can be compared to the desired constraints. Here, the constraints are set as the minimum (if the system size is governed by heating) or maximum (if the system size is governed by cooling) measured value for the GHX exiting fluid temperature, as this will be nearly equal to the heat pump EFT.

Other parameters such as borehole diameter, ground thermal properties, and borefield configuration are taken from the specifications for each system. These parameters, and (as available) the sources from which they were obtained, are summarized in Table 1. With the exception of the shank spacing, all values were taken directly from the experimental descriptions and subsequent thermal response testing. For the Stillwater system, in which measurements were taken for each borehole, the averages of the three measurements were used. The shank spacing in each case was assumed to follow the 'B' value given by Paul (1996)--the distance between the U-tube legs is equal to the distance between each leg and the borehole wall. When a U-tube is placed without spacers (which is assumed to be the case, as no indication to the contrary has been given), experiences show that the spacing tends toward the 'B' value, on average.

Loads are computed directly from the experimental data using the measured flow rate and temperature differential across the GHX; these loads are computed for each measured data point, and then processed into a monthly total/monthly peak format consistent with the hybrid time step procedure described by Cullin and Spitler (2011). For three of the systems, multiple years of data are available. As discussed above, for each system, some portion of the measured load data was chosen to make up the representative year used for the design methods. From these portions of the data, the average total monthly load was used for each month of the year, while the peak load magnitude and duration were determined following the load analysis procedure of Cullin and Spitler (2011) to assure that the selected peak representation matches an hourly simulation as closely as possible. Tables 2 through 5 show the simulation-based design tool load inputs—-both total for the month and peak, for both heating and cooling - for each location; the month number ' 1 ' corresponds to the first month of operation, which is not necessarily January in each case. Further details on the simulation-based design tool, including development of the g-functions as well as previous experimental validation of the tool, may be found in the works of Spitler (2000) and Cullin (2008). Additional validation of the design tool itself has been performed by Cullin, et al. (2014).

Handbook Method. The ASHRAE Handbook (2011) sets forth a ground heat exchanger design equation suitable for quick calculations, given as: 


$$
L_{c}=\frac{q_{a} R_{g a}+\left(q_{l c}-3.41 W_{c}\right)\left(R_{b}+P L F_{m} R_{g m}+R_{g d} F_{s c}\right)}{t_{g}-\frac{t_{w i}+t_{w o}}{2}-t_{p}}
$$

Where:

$$
\begin{aligned}
& L_{c} \text { is the required design length for cooling }[\mathrm{m} \text { or } \mathrm{ft}] \text {; } \\
& \text { and all other variables are defined in Table } 6 \text {. }
\end{aligned}
$$

Table 6 also lists the values provided for each experimental system, as taken from the experimental specifications, measurements, and estimations based on the recommended procedure of Kavanaugh and Rafferty (1997).

Heat transfer rates were computed as the net heat extracted from the ground $\left(q_{a}\right)$, summed over all hours, using the experimental data; values are negative when heat is being rejected. (Note that, due to this sign convention, compressor heat would add to the magnitude of the design block load term $q_{l c}$, although the equation may appear counterintuitive at first.) Since the loading directly on the ground was available instead of the building loads data, this was used instead of the combined design load/compressor work term. The part-load factors were computed directly from the hourly data, by dividing the total load for the month by the product of the peak load and number of hours in the month. For this calculation, the peak load is defined as the singular hourly load coincident with the peak temperature. Why has this definition been chosen? In practice, a system will not necessarily be sized to meet $100 \%$ of the load $100 \%$ of the time. The part-load factor is intended to represent an equivalent percentage of the time that the system would be running at full capacity; very high outlier loads would skew this value. If these high loads only occur for a small handful of hours throughout the year, then it might not make sense to oversize the equipment, and suffer inefficient performance during subpeak hours; this is very much the essence of the ASHRAE " $1 \%$ design condition", which intends to represent values that would only be exceeded $1 \%$ of the time. For instance, the peak cooling load for the Leicester system, about $500 \mathrm{~kW}(1700 \mathrm{kBtu} / \mathrm{h})$, occurs in mid-January; certainly the system would not be sized with this particular load in mind. In light of the fact that this work uses monitored data with measurement gaps, the load coincident with the peak temperature was selected as the peak load for computing the PLF; after all, in the end it is the peak temperature that is of the greatest interest, as this is what drives the size of the GHX. The Results section explores an alternate definition for the PLF using the value of the peak block load.

The borehole thermal resistance value $\left(R_{b}\right)$ was computed via the tabular data given in Kavanaugh and Rafferty (1997), even though these values were computed in greater detail as part of the monthly simulation tool 
analysis; this introduces some error, which will be discussed later. The undisturbed ground temperature $\left(t_{g}\right)$ was measured directly prior to the experiments in concurrence with thermal conductivity testing, while the heat pump design temperatures $\left(t_{w i}\right.$ and $\left.t_{w o}\right)$ are the experimental values when the maximum or minimum temperature occurs in the system. All other values are either calculated directly or assumed based on the procedures given in Kavanaugh and Rafferty (1997), using experimental parameters not shown in the table (such as ground thermal conductivity) where required.

The temperature penalty may be determined either from tabulated values (ASHRAE, 2011), or via direct computation (Kavanaugh and Rafferty, 1997). For this work, the temperature penalty was computed directly, using Equation 6 below:

$$
t_{p}=\frac{N_{4}+0.5 N_{3}+0.25 N_{2}+0.1 N_{1}}{N B} \cdot t_{p 1}
$$

Where:

$t_{p}$ is the temperature penalty for the borefield $\left[{ }^{\circ} \mathrm{C}\right.$ or $\left.{ }^{\circ} \mathrm{F}\right]$;

$t_{p l}$ is the temperature penalty for a single borehole adjacent to four other boreholes $\left[{ }^{\circ} \mathrm{C}\right.$ or $\left.{ }^{\circ} \mathrm{F}\right]$; and

$N_{i}$ is the number of boreholes in the field adjacent to $i$ other boreholes.

The temperature penalty of a single borehole $t_{p l}$ is determined by finding the heat stored in successive cylinders surrounding the borehole, such that heat that would ordinarily be diffused beyond the borehole separation distance would instead be stored within the area around the borehole itself:

$$
t_{p 1}=\frac{Q_{\text {stored }}}{\rho c_{p} d_{s e p}^{2} L}
$$

Where:

$Q_{\text {stored }}$ is the total heat stored in a cylindrical region extending from the midpoint between boreholes to infinity $[\mathrm{W}$ or Btu/h];

$\rho$ is the ground density $\left[\mathrm{kg} / \mathrm{m}^{3}\right.$ or $\left.\mathrm{lb} / \mathrm{ft}^{3}\right]$;

$c_{p}$ is the ground specific heat $\left[\mathrm{J} / \mathrm{kg}-\mathrm{K}\right.$ or Btu/lb- $\left.{ }^{\circ} \mathrm{F}\right]$;

$d_{\text {sep }}$ is the borehole separation distance $[\mathrm{m}$ or $\mathrm{ft}]$; and

$L$ is the borehole length [m or $\mathrm{ft}]$.

The short-circuit heat loss factor $\left(F_{s c}\right)$ was assumed as 1.04 in each case; this corresponds to a flow rate of approximately 3 GPM per ton $(0.16 \mathrm{~L} / \mathrm{s}$ per $\mathrm{kW})$ of loading for a system with a single borehole per parallel loop, the closest available equivalent to each of the experimental configurations. A brief sensitivity analysis indicated 
that the specific value for this factor (which is only shown by the authors to range from 1.01-1.06) produces a variation of less than $1 \%$ in the design length, in any case. The annual, monthly, and daily resistance values ( $R_{g a}, R_{g m}$, and $R_{g d}$, respectively) were also computed using the detailed method of Kavanaugh and Rafferty (1997). Fourier numbers for the total run time (one or more years, depending on system), monthly (30 days), and peak (six hours) pulses were computed, and the individual resistance terms were determined by using the "G-Factor" chart—not to be confused with the g-functions used in the simulation tool. While this chart is used in determining the thermal resistances, and was seemingly derived from cylinder source data, there is no source listed, nor is there any indication of what, exactly, the "G-factor" represents. Given that this is a logarithmic chart occupying only half a page in the Kavanaugh and Rafferty (1997) reference, there is a significant amount of uncertainty in reading values from this chart; sizing differences of $10 \%$ or more are possible due to the difficulty of reading the chart. Finally, it should be noted here that there is no real justification given by Kavanaugh and Rafferty (1997) for using six hours as the daily pulse, though it is used in examples. A more thorough examination of the load representation, as will be explained in the next section, is very likely to produce better results.

\section{Results}

For each of the four systems presented earlier, both the simulation-based design tool and the ASHRAE Handbook equation were used to size the VGHXs. Using measured loads on the ground heat exchanger and measured peak temperatures as inputs, a design method should be able to give a required depth that matches the actual depth. The depths predicted by the design methods are compared to the actual depths in Table 7 . The simulation-based design tool ("Design tool") gives results within 6\% of the experimental depth ("Actual") for all four systems. However, the ASHRAE Handbook ("Handbook") method consistently produces design lengths that significantly vary from the actual depths when actual experimental data is supplied as inputs.

Table 8 shows the oversizing (positive values) or undersizing (negative value) error for each combination of method and location. As Table 8 shows, for the Valencia system in particular, the Handbook error is greater than $100 \%$ - in other words, the specified design length is more than double what is actually required. For Atlanta, the Handbook method substantially undersizes the required VGHX depth; this would lead to increasing loop temperatures over time, with an associated decrease in efficiency or eventual equipment failure. In all cases, though, the length predicted by the simulation-based design tool matches the experimental depth to within $6 \%$. 
Why are there such differences between the Handbook equation and reality? This can be investigated using the simulation-based design tool. By incrementally changing the inputs to the design tool to more closely match what is assumed by the Handbook equation, the causes of the differences can be better understood. Firstly, the Handbook equation uses a constant load throughout the course of operation, with a magnitude equal to the average value, plus a peak "block load" for which no guidance is given on how to determine magnitude or duration; this peak block load is also coupled with the part-load factor for the design month to arrive at the value for the monthly thermal pulse. The design tool, on the other hand, uses a monthly time step, with loads input as monthly totals plus a monthly peak for both heating and cooling; Cullin (2008) describes how the peaks are selected in terms of magnitude and duration, while Cullin and Spitler (2011) show that this method of load representation performs very well, predicting design depths within $\pm 7 \%$ of what would be predicted using an hourly time step. First, the loads used with the simulation-based design tool were modified to more closely match the Handbook-style load representation by inputting a single average load applied every month plus a single peak load applied for 6 hours. This approach yielded a design length quite a bit closer to that obtained from the Handbook equation, accounting for at least half of the error. This can be seen in Figure 10, where the fourth column for each location (labeled "Design tool w/ handbook loading") represents this modification to the loads. As can be seen, the fourth column in each case comes much closer to the Handbook-style depth. Based on the results, it can be inferred that this approximation accounts for at least half of the error in the Handbook equation approach.

For a system that only operates for a single year, such as the one in Stillwater, it may be the case that the Handbook method may not be an adequate choice. The total load imbalance (extraction minus rejection) would certainly be different in the middle of the year, when the peak load might be expected to occur, than at the end of one or more years of long-term operation. While the Stillwater system is characterized by a high peak load in comparison to the total, the Handbook equation was reset to use only the short-term load data prior to the peak load-namely, the first four months (122 days) of operation. The "annual" load was replaced by the total imbalance up to the onset of the peak, $-432 \mathrm{~W}(-1470 \mathrm{Btu} / \mathrm{h})$. For the shorter operation, the annual ground resistance term was also recalculated for a four-month duration, to a value of $0.059 \mathrm{~m}-\mathrm{K} / \mathrm{W}\left(0.102 \mathrm{~h}-\mathrm{ft}-{ }^{\circ} \mathrm{F} / \mathrm{Btu}\right)$. Finally, the temperature penalty, due to this shorter operation, is negligible (less than 0.01 degree). Other values remained as calculated in Table 6. For this test, the Handbook equation produces a design length of $123 \mathrm{~m} \mathrm{(403}$ $\mathrm{ft})$ per borehole; this is a decrease of about $5 \%$ from the previous value of $132 \mathrm{~m}(432 \mathrm{ft})$. The overall error 
dropped from $76 \%$ to $64 \%$, so for this case, the short design period is not a major contributing factor to the inaccuracy produced by the Handbook method.

A secondary source of error in the Handbook method comes from the borehole thermal resistance. As detailed by Kavanaugh and Rafferty (1997), determination of the borehole thermal resistance involves two components: a base value determined from a table that contains four U-tube diameters for either water or $20 \%$ propylene glycol at three discrete flows as the operating fluid, plus an "adjustment" for grouting dictated by the U-tube diameter, one of three discrete borehole diameters, and selection of three grout and three soil conductivities. Given that the differences between entries are nonlinear, interpolation (triple interpolation, at times) is of uncertain reliability. For this work, though, simple linear interpolation was used to determine the value used in the Handbook equation. As shown in Table 9, this is at times $30 \%$ or more different than the value used in the design tool. The design tool's borehole thermal resistances are computed with the multipole method (Bennet et al., 1987; Claesson and Hellström, 2011); for the Stillwater system at least, this value agrees with the value reported as a result of thermal response testing by Hern (2004).

When the value for borehole thermal resistance determined from the Handbook tables is applied in the design tool, along with the simplified load representation, two of the four cases move substantially closer to the Handbook design length, as shown in Figure 10 and the error table in Table 10. One does not change much as the Handbook's resistance was actually very close $(\sim 2 \%$ difference $)$ to the multipole value, and the final becomes even more undersized since this is the lone case for which the tabulated resistance is lower than that obtained with the multipole method. This is also visible in Figure 10 ("Design tool w/ handbook loading and BTR").

Secondary to the uncertainty in the borehole thermal resistance is the inherent inaccuracy in reading values from the G-factor chart in Kavanaugh and Rafferty (1997). With G-factors required for the annual, monthly, and sub-daily resistances, differences in size of $10 \%$ or more are possible based solely on the difficulty in reading the logarithmic graph. While this is obviously source of error, there is no way for the design engineer to produce a more accurate value based on the information given by Kavanaugh and Rafferty (1997).

There are other possible representations for the part-load factor. If, instead of the load coincident with the peak temperature, the peak block load (defined as the highest average load over any six consecutive hours) were to be used, the part-load factors would be 0.06 for Stillwater, 0.07 for Valencia, 0.27 for Atlanta, and 0.12 for Leicester. With the exception of Atlanta, none of these are especially close to the values determined from the load coincident with the peak temperature. Additionally, they are all very small, particularly for the design 
month; especially for Stillwater and Valencia, they suggest a peak load nearly 20 times the value of the average load for the month. The load profiles in Figures 2 and 4 do not provide any visual confirmation that this is true, however. Nevertheless, if these alternative PLFs were used instead, and all other parameters kept the same, the resulting GHX sizes would be 75m (246ft) for Stillwater, 88m (287ft) for Valencia, 92m (303ft) for Atlanta, and $133 \mathrm{~m}$ (436ft) for Leicester. This Stillwater size is a match to the actual length (to within significant digits), while the percent errors for the other three drop to $75 \%, 33 \%$, and $-24 \%$, respectively. It should definitely be noted, though, that the exact matching for the Stillwater case is driven by coincidence: the peak block load was defined to be six hours in duration without any concrete engineering justification. Selecting a shorter block period would cause the PLF to decrease further (since the magnitude of the load would increase by virtue of removing one or more lower-valued hours), and the resulting design length would then be undersized. Similarly, choosing a longer block period would decrease the magnitude of the peak block load, thereby increasing the PLF and the GHX design length as well.

Using the experimental parameters as inputs to the Handbook design equation, and following the detailed procedure of Kavanaugh and Rafferty (1997) for determining the remainder of the inputs, errors from $+103 \%$ to $-22 \%$ in the VGHX design length were encountered. Of this, the loading scheme seems uncorrectable, as any adaptation of the Handbook equation toward a more detailed loading scheme (even using monthly total and peak loads, as the simulation-based design tool does) would necessitate something akin to a complete system simulation—-something that the simulation-based design tool already achieves. Regardless, it can be inferred that the simple representation of loads in the Handbook equation can account for up to roughly half of the sizing error (in the Valencia and Leicester cases). It seems to account for more than half of the error in the Stillwater case and less than half of the error in the Atlanta case. Furthermore, inaccuracies in the borehole thermal resistance increase the error further, accounting for around a quarter of the error in the Leicester and Stillwater systems, and more in the Atlanta system (although the total error in this case is smaller, while the absolute error in borehole thermal resistance is largest). Other contributing factors include the inherent uncertainty in determining the G-factors, and the effects of an arbitrary definition of the peak block load as pertaining to the calculation of the part-load factor. It is possible to apply a more accurate resistance value in the Handbook equation, whether it would be determined analytically by the multipole method or empirically from thermal response test results; however, it is still impossible to correct the load representation without drastically altering the Handbook equation. 


\section{Conclusions}

This work has presented an assessment of two methods for sizing vertical ground heat exchangers for use in ground source heat pump systems: the ASHRAE Handbook design equation, as set forth in detail by Kavanaugh and Rafferty (1997); and a simulation-based design tool (Spitler, 2000; Cullin, 2008). This assessment was performed by using the two methods to "size" GHXs based on real systems, with specifications, loads, and temperature constraints dictated by physical parameters and experimental measurements.

The simulation-based design tool performs very well, predicting GHX lengths within $5 \%$ in all cases. Though experimental uncertainties are not readily available for all systems, Cullin et al. (2014) showed that, for Valencia, this error falls within the combined uncertainty of thermal conductivity and load measurements. In any case, Cullin and Spitler (2011) have shown that going from a pure hourly simulation to a hybrid monthlyplus-peak-hours time step introduces a difference of roughly $7 \%$ into the design length over the course of a multi-year simulation. So, then, the simulation-based design tool is essentially as accurate as could be reasonably expected, given the limitations of a non-hourly simulation as well as experimental uncertainty.

The Handbook design equation, however, produced results that are inconsistent, at best. The Stillwater system was sized at $26 \%$ more than the actual installed depth, with Leicester somewhat larger at $60 \%$ oversized; Valencia was greater than $100 \%$ in error-more than twice the size that was actually necessary. Perhaps more seriously than the excess cost associated with extremely oversized systems, is that the Atlanta system was undersized by more than $20 \%$; this could lead to poor performance, equipment failure, and unhappy clients when heat pump temperatures become too high. Exploring the load representation and borehole thermal resistance explains much of the differences between the Handbook equation and the simulation tool. While a more accurate borehole thermal resistance could easily be integrated by utilizing a more accurate method for determining it, it would be very difficult to modify the Handbook equation in such a way as to improve the load representation, and at the same time clarifying vague parameter definitions, while still retaining computational simplicity. Even if a monthly (or even seasonal) profile were selected instead of one annual average valueplus peaks for each — it would require consideration of the effect of all previous loads on the current value; since this is, in essence, what the simulation-based design tool already does, it is likely not feasible to try to adapt the Handbook equation as it exists in its current form.

As discussed in the Measured Data section, the four locations chosen for the comparison were those for which data were available and which came close to the ideal described there. As noted, such data sets are remarkably rare. The four data sets utilized here were collected at great expense and effort; presumably that is 
why there are so few publicly available data sets that even approach the ideal. The authors would welcome publication of additional data sets. It would be particularly useful to collect and publish data for larger systems, systems that are cooling-dominated or heating-dominated, systems with deeper boreholes, and systems with groundwater-filled boreholes.

\section{References}

ASHRAE, 2011. ASHRAE Handbook--HVAC Applications. Atlanta: ASHRAE.

Bennet, J., J. Claesson, and G. Hellström. 1987. Multipole Method to Compute the Conductive Heat Flows to and Between Pipes in a Composite Cylinder. Notes on Heat Transfer 3-1987, Department of Building Technology and Mathematical Physics, University of Lund, Sweden.

Bernier, M.A., A. Chahla, and P. Pinel. 2008. Long-term ground temperature changes in geoexchange systems. ASHRAE Transactions 114(2): 342-350.

Capozza, A., M. De Carli, and A. Zarrella. 2012. Design of borehole heat exchanger for groundsource heat pumps: A literature review, methodology comparison and analysis on the penalty temperature. Energy and Buildings 55: 369-379.

Claesson, J., and G. Hellström. 2011. Multipole method to calculate borehole thermal resistances in a borehole heat exchanger. HVAC\&R Research 17(6): 895-911.

Cullin, J.R. 2008. Improvements in design procedures for ground source and hybrid ground source heat pump systems. Master's Thesis, Oklahoma State University, Stillwater OK.

Cullin, J.R., and J.D. Spitler. 2011. A computationally efficient hybrid time step methodology for simulation of ground heat exchangers. Geothermics 40(2): 144-156.

Cullin, J.R., C. Montagud, F. Ruiz-Calvo, and J.D. Spitler. 2014. Experimental validation of ground heat exchanger design methodologies using real monitored data. ASHRAE Transactions 120(2): pages pending.

Cullin, J.R., E. Lee, amd J.D. Spitler. 2013. Preliminary investigation of the effect of horizontal piping on the performance of a vertical ground heat exchanger system. ASHRAE Transactions 119(2): 302-311.

Environmental Protection Agency: http://www.epa.gov/region1/eco/energy/re geothermal.html, $14 / 03 / 2013$.

Eskilson, P. 1987. Thermal analysis of heat extraction boreholes. Doctoral Thesis, Lund University, Sweden.

Fisher, D.E., A. Murugappan, S.K. Padhmanabhan, and S.J. Rees. 2006. Implementation and validation of ground-source heat pump system models in an integrated building and system simulation environment. HVAC\&R Research 12(3a): 693-710.

Fossa, M. 2011. The temperature penalty approach to the design of borehole heat exchanger for heat pump applications. Energy and Buildings 43(6):1473-1479.

Hellström, G., B. Sanner, M. Klugescheid, T. Gonka, and S. Mårtensson. 1997. Experiences with the borehole heat exchanger software EED. Proceedings of Megastock Conference 1997, Sapporo, Japan.

Hern, S. 2004. Design of an experimental facility for hybrid ground source heat pump systems. M.S. Thesis, Oklahoma State University, Stillwater OK.

Kavanaugh, S.P. 1995. A design method for commercial ground-coupled heat pumps. ASHRAE Transactions_101(2):1088-1094. 
Kavanaugh, S.P., and K. Rafferty. 1997. Ground-source heat pumps: Design of geothermal systems for commercial and industrial buildings. Atlanta: ASHRAE.

Kurevija, T., D. Vulin, and V. Krapec. 2012. Effect of borehole array geometry and thermal interferences on ground source heat pump system. Energy Conversion and Management 60:134142.

Liu, X., and G. Hellström. 2006. Enhancements of an integrated simulation tool for ground-source heat pump system design and energy analysis. Proceedings of Ecostock 2006, Pomona NJ.

Montagud, C., J.M. Corberán, J.M., Á. Montero, and J.F. Urchueguía. 2011. Analysis of the energy performance of a Ground Source Heat Pump system after five years of operation. Energy and Buildings 43: 3618-3626.

Naicker, S.S., and S.J. Rees. 2011. Monitoring and performance analysis of large non-domestic ground source heat pump installation. Proceedings of 2011 CIBSE Technical Symposium, Leicester UK, 6-7 September.

Parsons, B. A living laboratory: ASHRAE's renovated headquarters. Canadian Consuting Engineer 49(7): 31-33.

Paul, N.D. 1996. The effect of grout thermal conductivity on vertical geothermal heat exchanger design and performance. M.S. Thesis, South Dakota State University.

Philippe, M., M. Bernier, and D. Marchio. 2010. Sizing calculation spreadsheet: Vertical geothermal borefields. ASHRAE Journal 52(7):20-28.

Shonder, J.A., V. Baxter, J. Thornton, and P. Hughes. 2000. A comparison of vertical ground heat exchanger software for commercial applications. ASHRAE Transactions 106(1): 831-842.

Spitler, J.D. 2000. GLHEPRO-A design tool for commercial building ground loop heat exchangers. Proceedings of the Fourth International Heat Pumps in Cold Climates Conference, Aylmer, Québec, 17-18 August.

Spitler, J.D., and J.R. Cullin. 2008. Misconceptions regarding design of ground-source heat pump systems. Proccedings of the World Renewable Energy Congress, Glasgow, Scotland, 20-25 July.

Staiti, M. 2014. The sizing of borehole heat exchangers for ground source heat pumps: A comparison between tow methods. Master's thesis, Politecnico di Milano, Milan, Italy.

Underwood, C.P., and J.D. Spitler. 2007. Analysis of vertical ground loop heat exchangers applied to buildings in the UK. Building Service Engineering, Research and Technology 28: 133-159. 
Figure 1. Stillwater experimental daily average temperatures

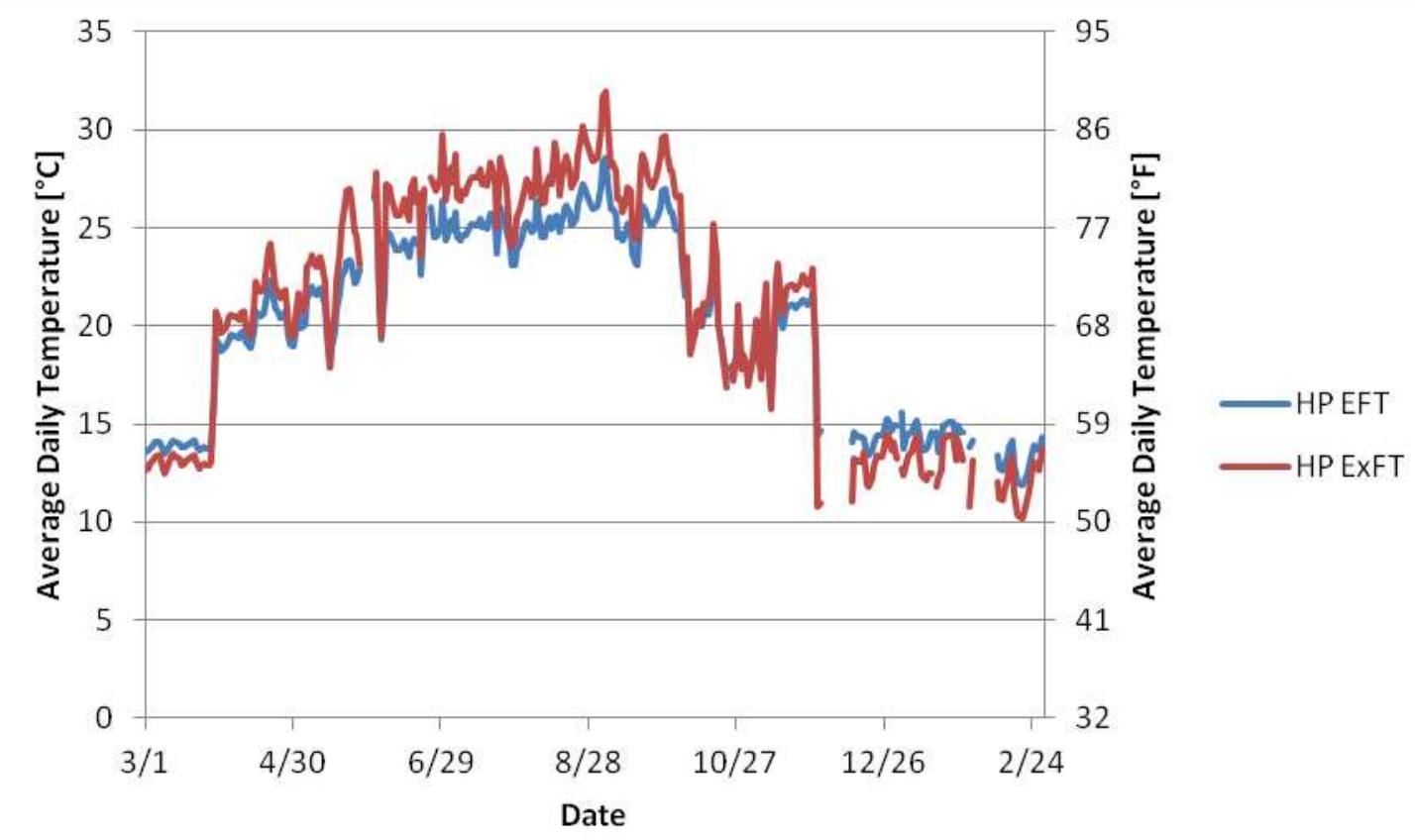

Figure 2. Stillwater experimental daily total ground heat extraction

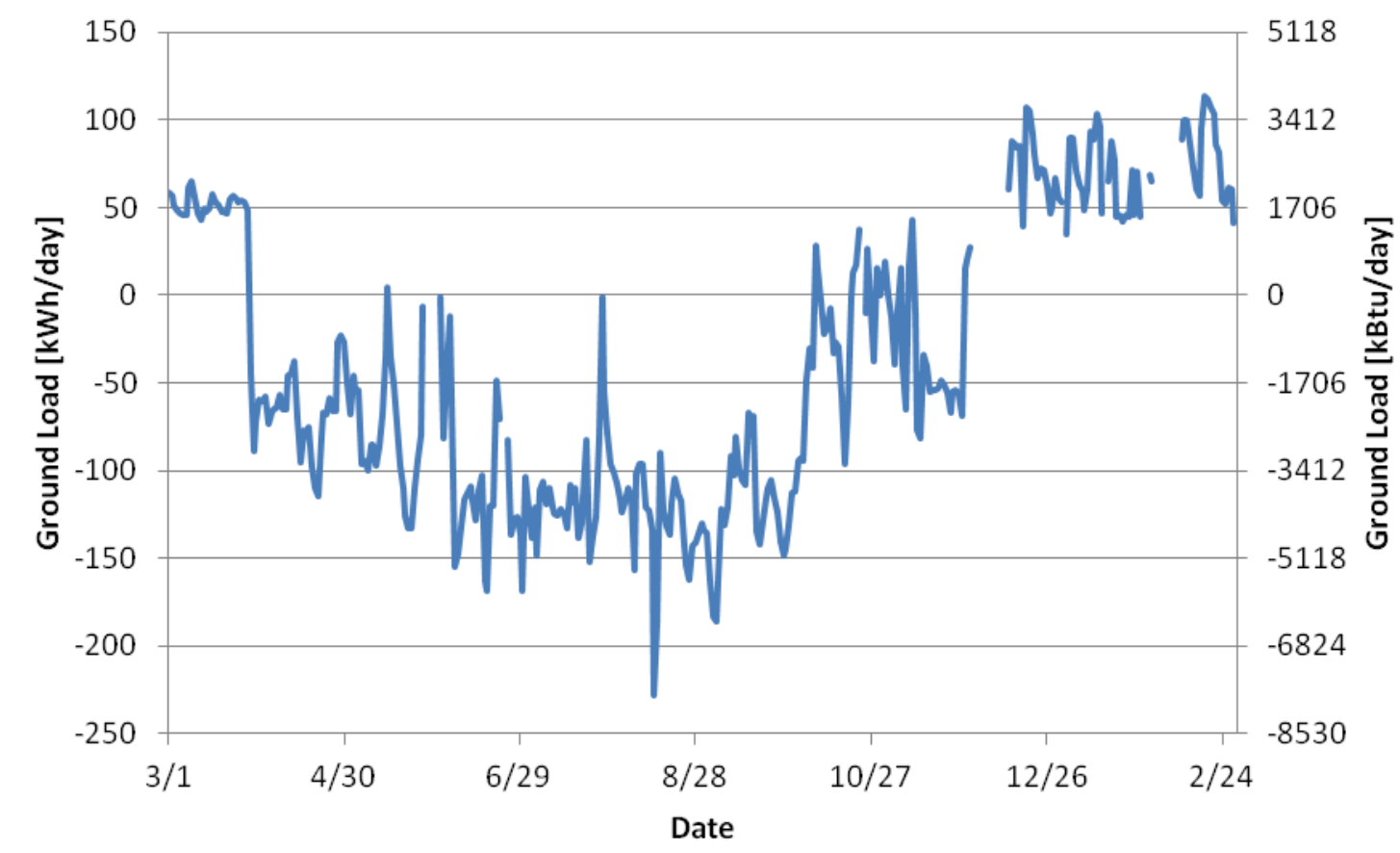

Figure 3. Valencia sixth-year experimental daily average temperatures 


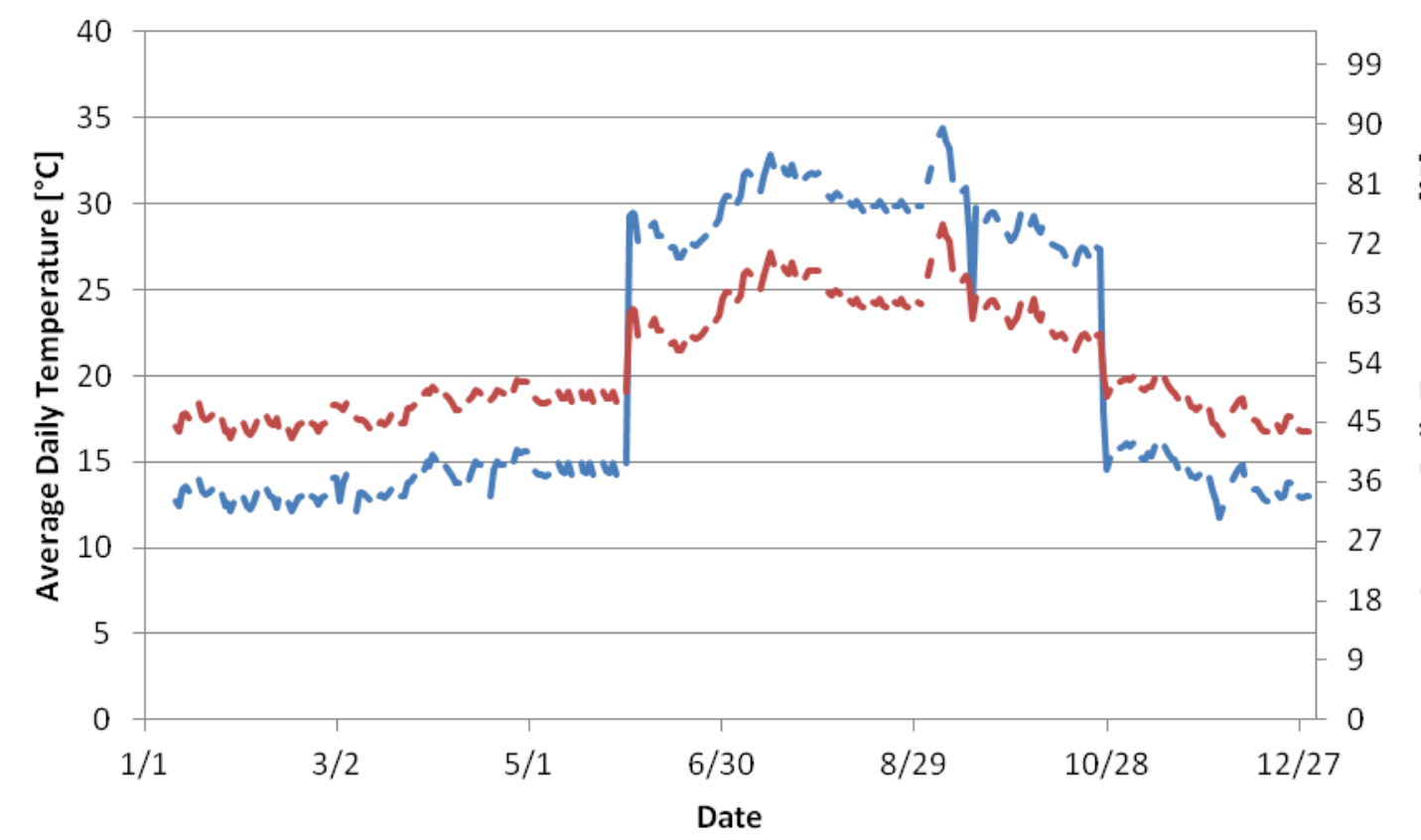

HPEFT

Figure 4. Valencia sixth-year experimental daily total ground heat extraction

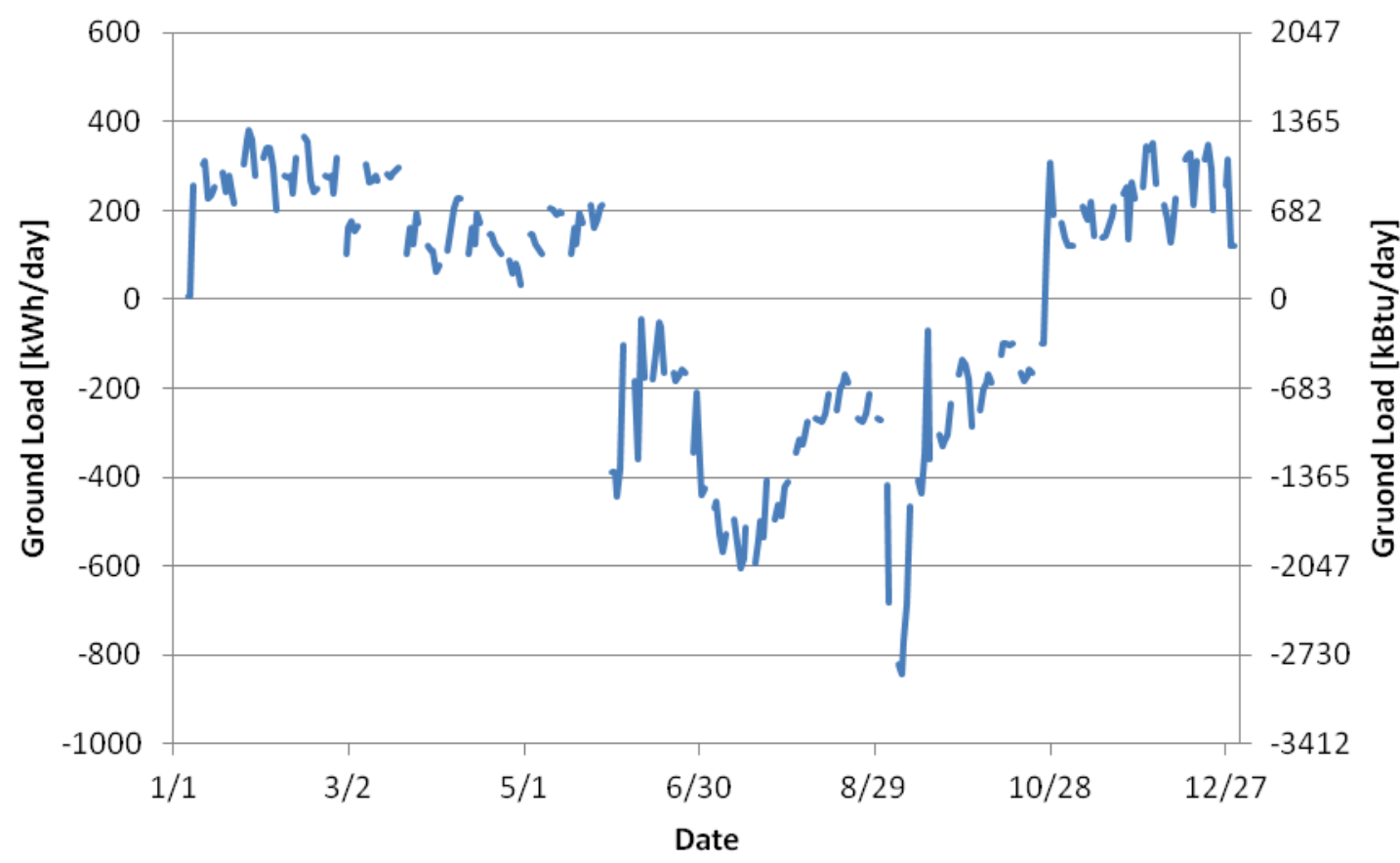

Figure 5. Atlanta first-year experimental daily average temperatures 


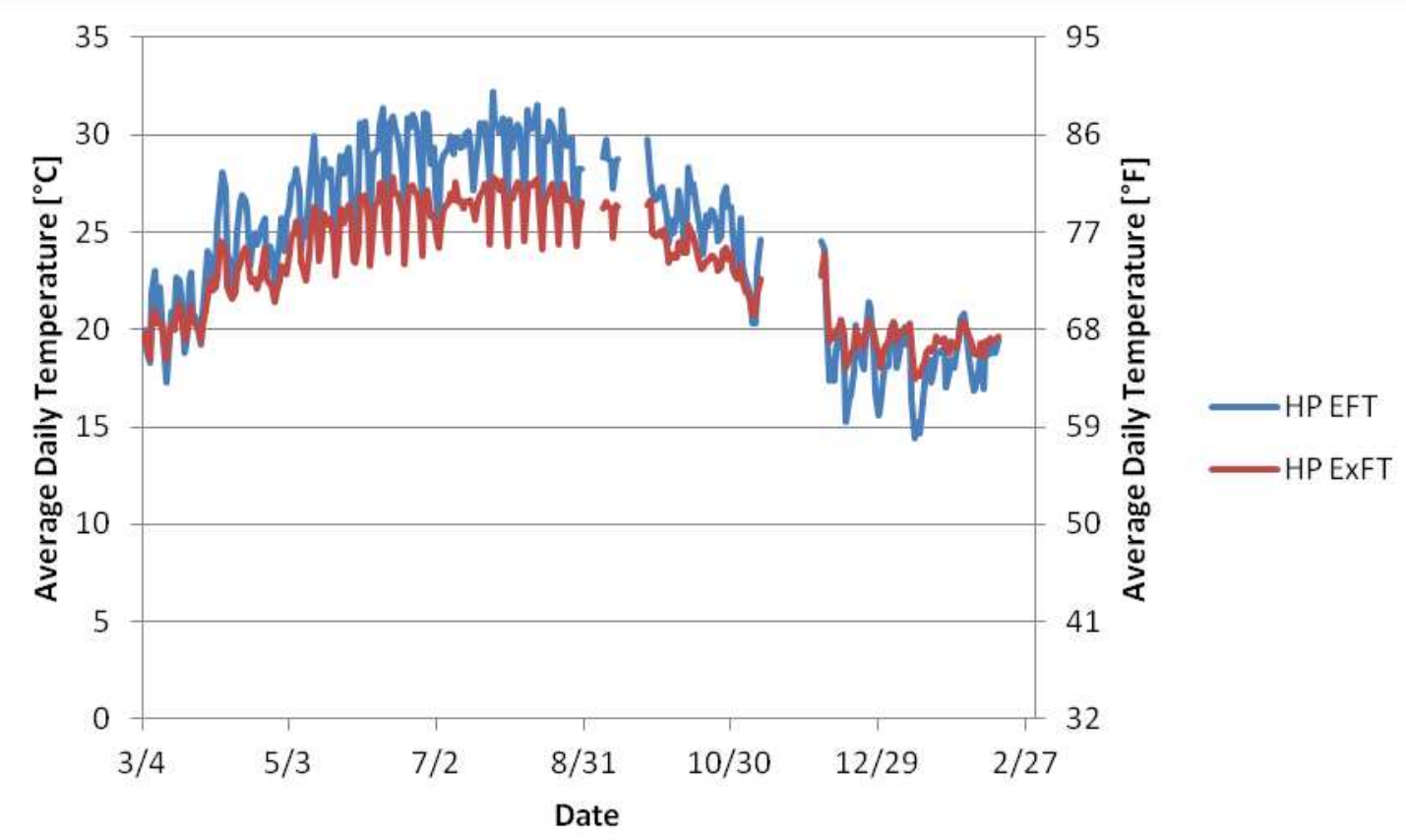

Figure 6. Atlanta first-year experimental daily total ground heat extraction

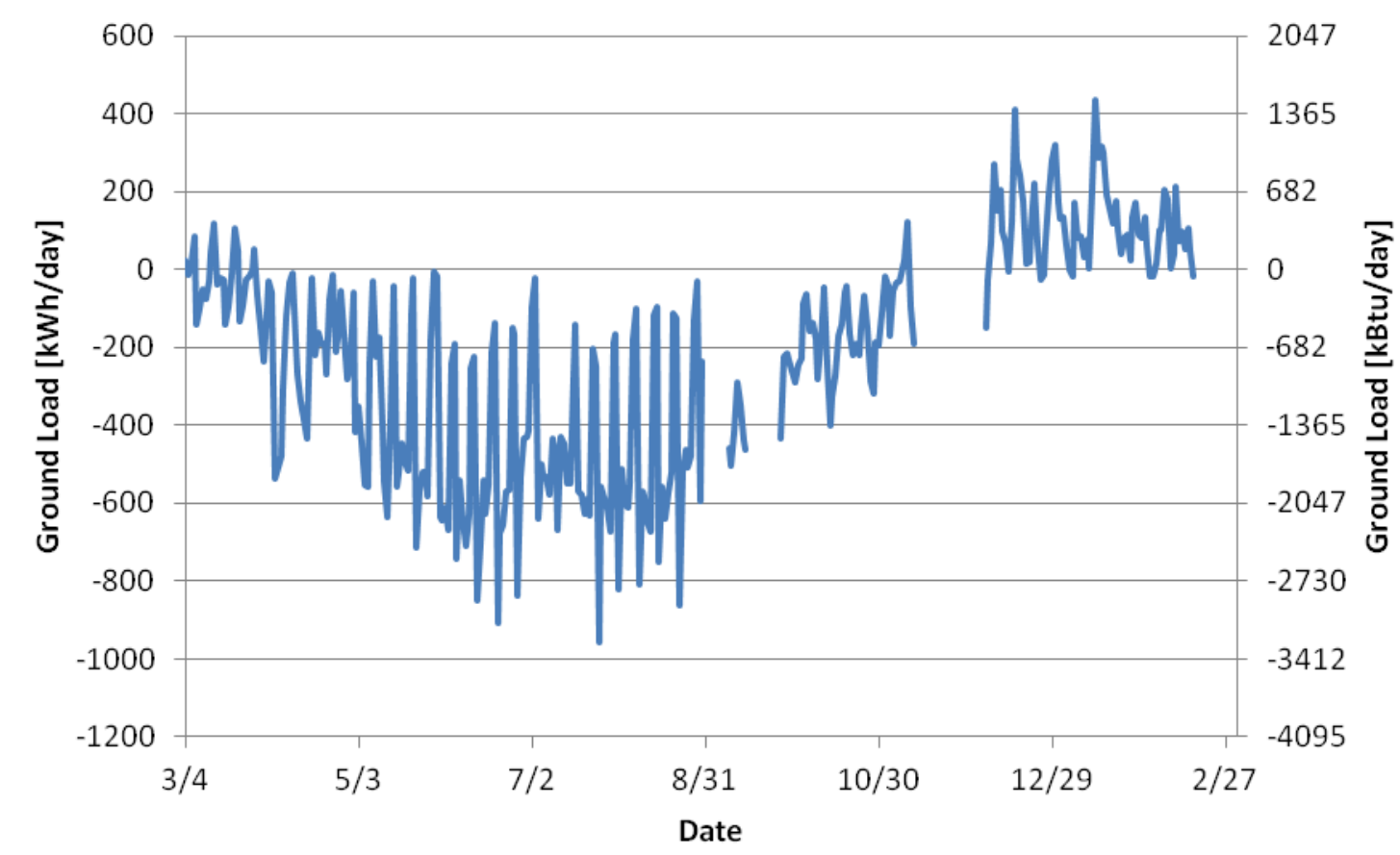

Figure 7. Atlanta predicted, actual, and modeled net monthy heat rejection 


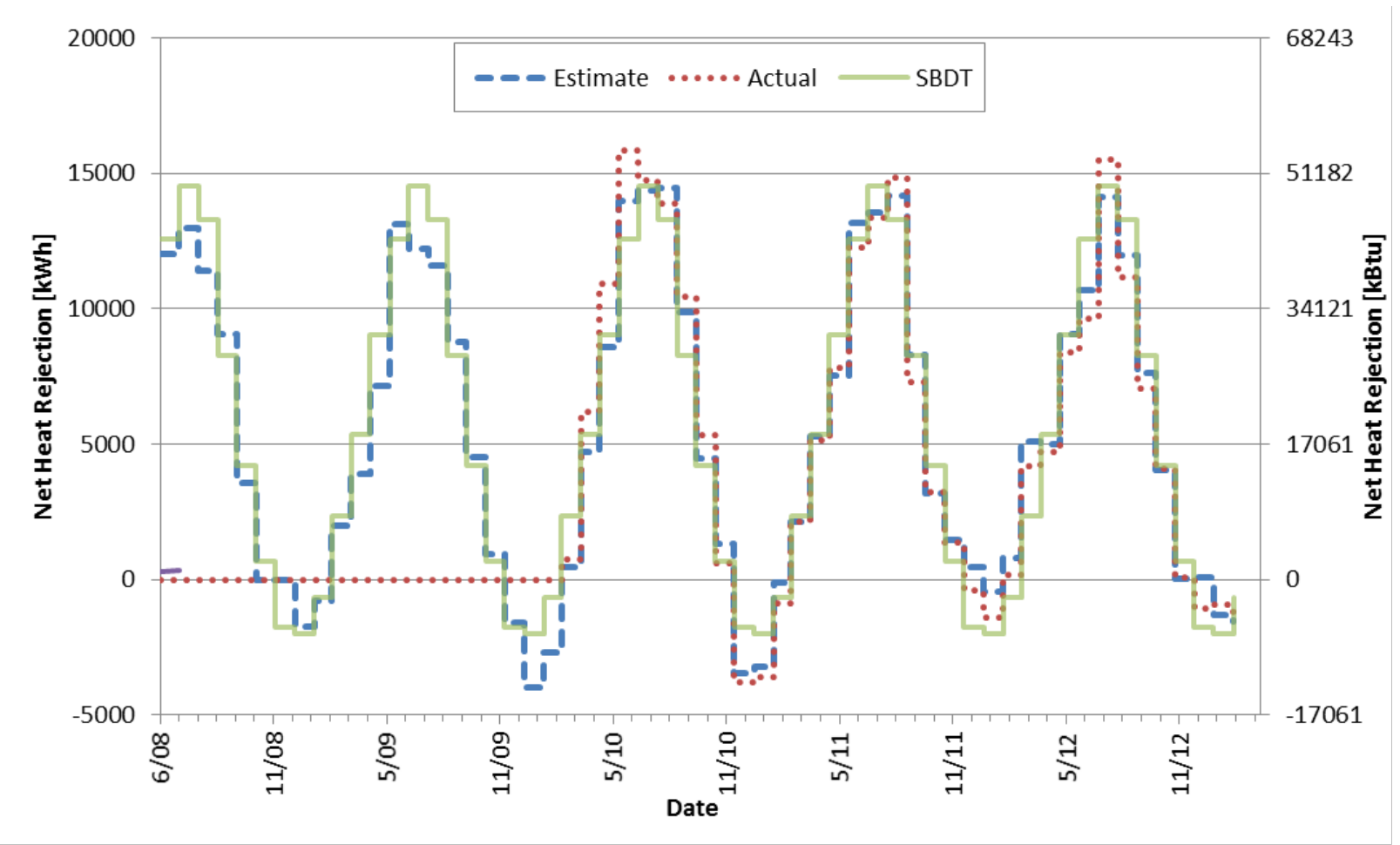

Figure 8. Leicester experimental daily average temperatures

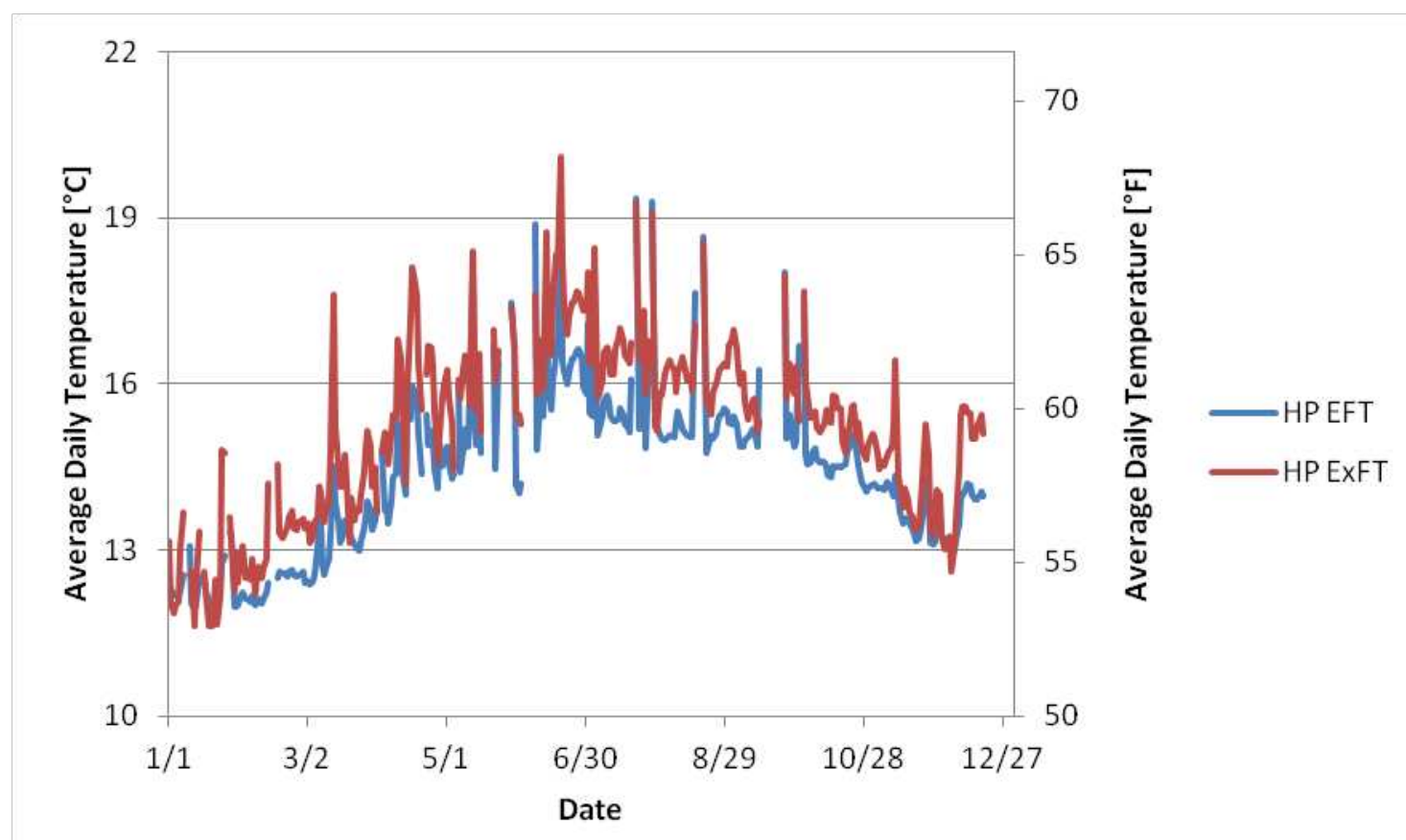


Figure 9. Leicester experimental daily total heat rejection

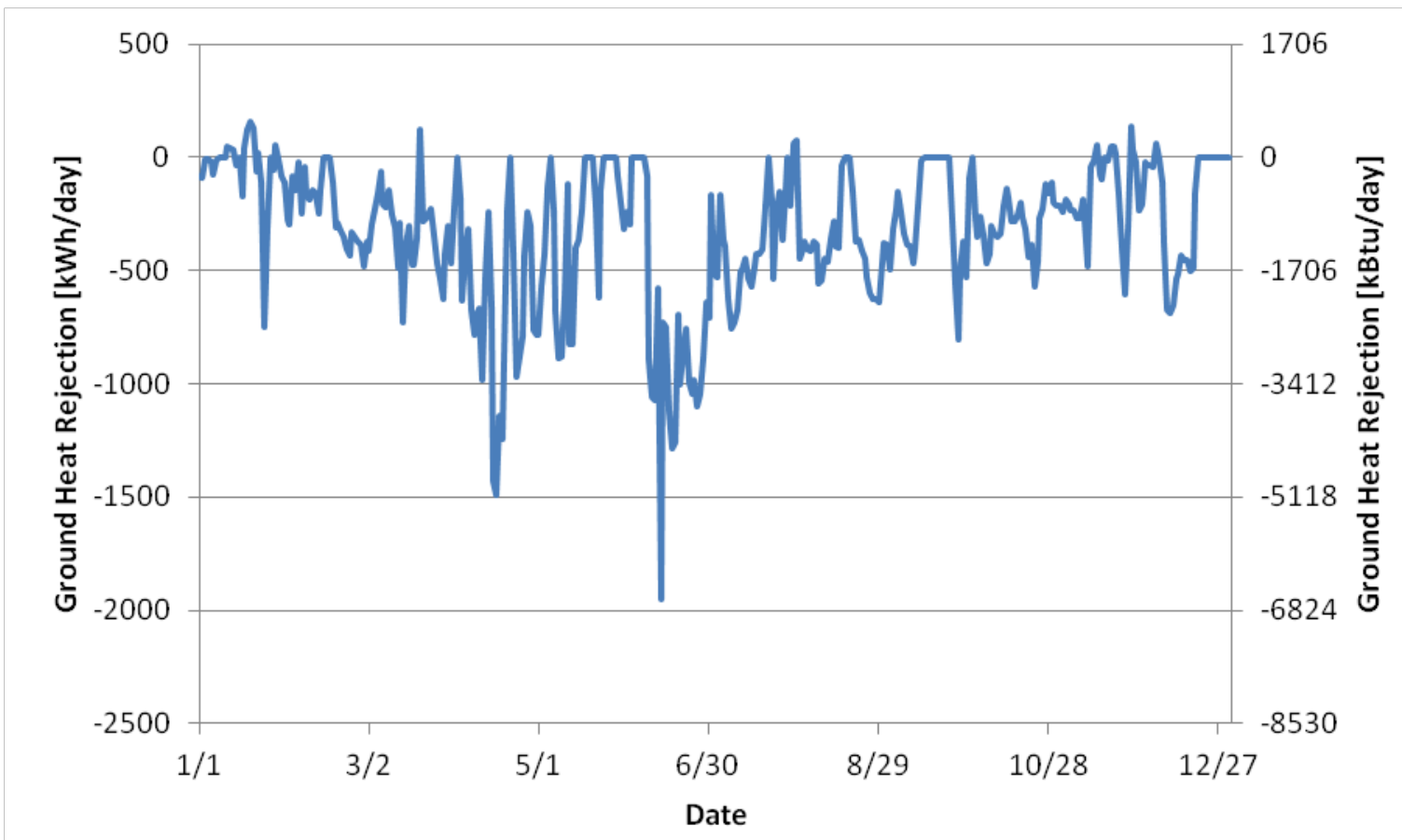

Figure 10. Extended comparison of design lengths
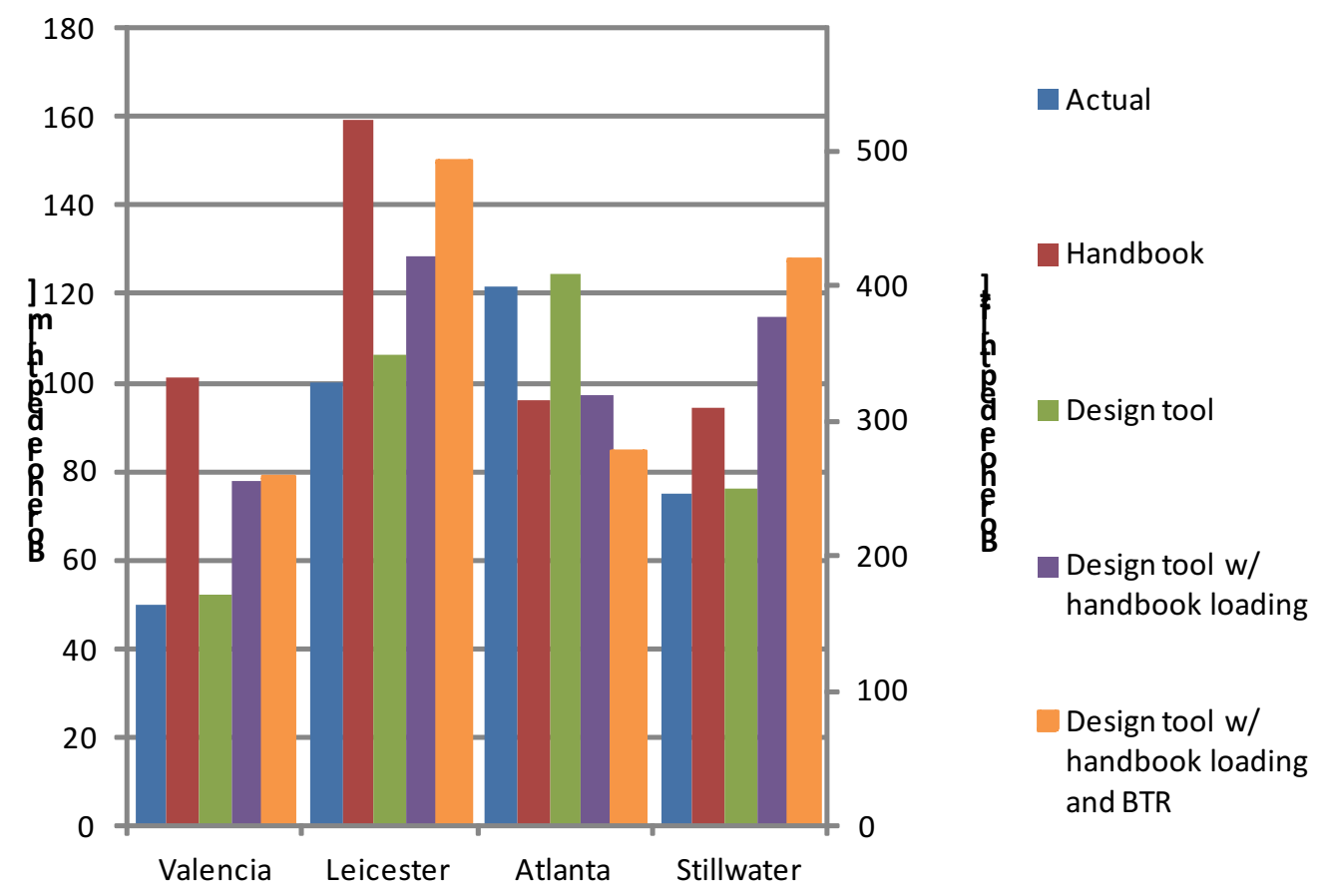

\begin{tabular}{|c|c|c|c|c|}
\hline Facility location & Valencia & Leicester & Atlanta & Stillwater \\
\hline REFERENCE & $\begin{array}{c}\text { Montagud et al., } \\
2011\end{array}$ & $\begin{array}{c}\text { Naicker and Rees, } \\
2011\end{array}$ & --- & Hern, 2004 \\
\hline Borehole depth, $\mathrm{m}$ (ft) & $50(164)$ & $100(328)$ & $122(400)$ & $75(246)$ \\
\hline Borehole spacing, $\mathrm{m}$ (ft) & $3(10)$ & $10(33)$ & $7.6(25)$ & $9(30)$ \\
\hline Borehole diameter, $\mathrm{mm}$ (in) & $150(5.9)$ & $126(5.0)$ & $140(5.5)$ & $114(4.5)$ \\
\hline
\end{tabular}


U-tube inner diameter, $\mathrm{mm}$ (in)

U-tube outer diameter, $\mathrm{mm}$ (in)

Shank spacing, $\mathrm{mm}$ (in)

Undisturbed ground temperature, ${ }^{\circ} \mathrm{C}\left({ }^{\circ} \mathrm{F}\right)$

Ground thermal conductivity, W/m-K (Btu/hr-ft- $\left.{ }^{\circ} \mathrm{F}\right)$

Grout thermal conductivity, W/m-K $\left(\mathrm{Btu} / \mathrm{hr}-\mathrm{ft}-{ }^{\circ} \mathrm{F}\right)$

$\begin{array}{ll}23.4(0.92) & 34.5(1.36) \\ 25.4(1.00) & 42.5(1.66) \\ 44.6(1.76) & 13.9(0.55) \\ 19.5(67.1) & 13.2(55.8) \\ 1.6(0.92) & 3.2(1.8) \\ 1.6(0.92) & 2.0(1.2)\end{array}$

$34.5(1.36)$

$21.8(0.89)$

$42.5(1.66) \quad 26.7(1.05)$

$18.5(0.73) \quad 20.2(0.80)$

$19.5(67.1) \quad 17.3(63.1)$

$3.3(1.9) \quad 2.6(1.5)$

$1.7(0.98) \quad 1.6(0.92)$

\begin{tabular}{|c|cccc|}
\hline \multicolumn{5}{|c|}{ Table 2. SBDT GHX loads for Stillwater } \\
\hline Month & $\begin{array}{c}\text { Total Heating, } \\
\text { kWh (kBtu) }\end{array}$ & $\begin{array}{c}\text { Total Cooling, } \\
\text { kWh }(\mathbf{k B t u})\end{array}$ & $\begin{array}{c}\text { Peak Heating, } \\
\mathbf{k W}(\mathbf{k B t u} / \mathbf{h})\end{array}$ & $\begin{array}{c}\text { Peak Cooling, } \\
\mathbf{k W}(\mathbf{k B t u} / \mathbf{h})\end{array}$ \\
\hline 1 & $1959(6683)$ & $160(545)$ & $7.5(25.5)$ & $13.5(46)$ \\
2 & $75(255)$ & $1320(4503)$ & $0.5(1.7)$ & $9(30.6)$ \\
3 & $66(225)$ & $1701(5802)$ & $3.2(10.8)$ & $9.7(32.9)$ \\
4 & $1(4)$ & $2704(9227)$ & $1(3.3)$ & $12.5(42.8)$ \\
5 & $13(44)$ & $3271(11161)$ & $1.4(4.8)$ & $10.1(34.6)$ \\
6 & $2(8)$ & $3775(12881)$ & $0.5(1.8)$ & $10.3(35)$ \\
7 & $23(77)$ & $3366(11486)$ & $1.8(6.1)$ & $9.9(33.7)$ \\
8 & $621(2117)$ & $1133(3867)$ & $4.8(16.3)$ & $9.4(32.1)$ \\
9 & $452(1542)$ & $1009(3441)$ & $9(30.6)$ & $9.3(31.8)$ \\
10 & $1504(5132)$ & $0(0)$ & $9.2(31.4)$ & $0(0)$ \\
11 & $1698(5795)$ & $0(0)$ & $8.8(30)$ & $0(0)$ \\
12 & $1609(5489)$ & $0(0)$ & $7.5(25.7)$ & $0(0)$ \\
\hline
\end{tabular}

\begin{tabular}{|c|cccc|}
\hline \multicolumn{5}{c}{ Table 3. SBDT GHX loads for Atlanta } \\
\hline Month & $\begin{array}{c}\text { Total Heating, } \\
\text { kWh (kBtu) }\end{array}$ & $\begin{array}{c}\text { Total Cooling, } \\
\text { kWh (kBtu) }\end{array}$ & $\begin{array}{c}\text { Peak Heating, } \\
\text { kW (kBtu/h) }\end{array}$ & $\begin{array}{c}\text { Peak Cooling, } \\
\text { kW (kBtu/h) }\end{array}$ \\
\hline 1 & $1314(4485)$ & $2476(8448)$ & $51.3(175.1)$ & $29.9(102)$ \\
2 & $72(244)$ & $6104(20828)$ & $20.7(70.7)$ & $60.1(205.1)$ \\
3 & $4(13)$ & $12063(41158)$ & $0.7(2.4)$ & $77.1(262.9)$ \\
4 & $6(20)$ & $15414(52591)$ & $1.2(4.2)$ & $87(296.9)$ \\
5 & $7(24)$ & $15023(51259)$ & $1.1(3.8)$ & $219.8(750)$ \\
6 & $8(27)$ & $13624(46486)$ & $1.2(4.1)$ & $89.7(306.1)$ \\
7 & $31(107)$ & $7568(25820)$ & $5.7(19.6)$ & $66.6(227.3)$ \\
8 & $1358(4633)$ & $3307(11284)$ & $48.5(165.3)$ & $54.5(186.1)$ \\
9 & $4719(16100)$ & $653(2227)$ & $49.6(169.3)$ & $14.7(50.3)$ \\
10 & $4351(14846)$ & $750(2559)$ & $46.6(159)$ & $13.4(45.9)$ \\
11 & $1698(5795)$ & $0(0)$ & $8.8(30)$ & $0(0)$ \\
12 & $1609(5489)$ & $0(0)$ & $7.5(25.7)$ & $0(0)$ \\
\hline
\end{tabular}

\begin{tabular}{|c|cccc|}
\hline \multicolumn{5}{|c|}{ Table 4. SBDT GHX loads for Valencia } \\
\hline Month & $\begin{array}{c}\text { Total Heating, } \\
\text { kWh (kBtu) }\end{array}$ & $\begin{array}{c}\text { Total Cooling, } \\
\text { kWh (kBtu) }\end{array}$ & $\begin{array}{c}\text { Peak Heating, } \\
\text { kW (kBtu/h) }\end{array}$ & $\begin{array}{c}\text { Peak Cooling, } \\
\text { kW (kBtu/h) }\end{array}$ \\
\hline 1 & $1640(5595)$ & $0(0)$ & $12.3(41.8)$ & $0(0)$ \\
2 & $1628(5556)$ & $0(0)$ & $12.4(42.3)$ & $0(0)$ \\
3 & $1372(4682)$ & $0(0)$ & $12.1(41.1)$ & $0(0)$ \\
4 & $745(2543)$ & $0(0)$ & $11.6(39.4)$ & $0(0)$ \\
5 & $0(0)$ & $1542(5260)$ & $0(0)$ & $17.1(58.3)$ \\
\hline
\end{tabular}




\begin{tabular}{|c|cccc|}
\hline 6 & $0(0)$ & $2405(8207)$ & $0(0)$ & $17.4(59.2)$ \\
7 & $0(0)$ & $3081(10513)$ & $0(0)$ & $16.1(54.9)$ \\
8 & $0(0)$ & $1759(6001)$ & $0(0)$ & $15.2(52)$ \\
9 & $0(0)$ & $1578(5383)$ & $0(0)$ & $14.2(48.5)$ \\
10 & $0(0)$ & $1123(3833)$ & $0(0)$ & $13.6(46.5)$ \\
11 & $758(2587)$ & $0(0)$ & $9.8(33.4)$ & $0(0)$ \\
12 & $1248(4257)$ & $0(0)$ & $11.3(38.6)$ & $0(0)$ \\
\hline
\end{tabular}

\begin{tabular}{|c|cccc|}
\hline \multicolumn{5}{|c|}{ Table 5. SBDT GHX loads for Leicester } \\
\hline \multirow{2}{*}{ Month } & $\begin{array}{c}\text { Total Heating, } \\
\text { kWh (kBtu) }\end{array}$ & $\begin{array}{c}\text { Total Cooling, } \\
\text { kWh (kBtu) }\end{array}$ & $\begin{array}{c}\text { Peak Heating, } \\
\text { kW (kBtu/h) }\end{array}$ & $\begin{array}{c}\text { Peak Cooling, } \\
\text { kW (kBtu/h) }\end{array}$ \\
\hline 1 & $2618(8932)$ & $7989(27259)$ & $25.8(88.1)$ & $96.2(328.3)$ \\
2 & $7391(25218)$ & $13665(46623)$ & $40.6(138.4)$ & $49.5(168.7)$ \\
3 & $4536(15478)$ & $15106(51543)$ & $26.9(91.6)$ & $136.2(464.7)$ \\
4 & $2226(7596)$ & $20903(71319)$ & $27.4(93.6)$ & $166(566.4)$ \\
5 & $1497(5107)$ & $11052(37709)$ & $26.9(91.6)$ & $138.9(474)$ \\
6 & $1870(6379)$ & $23886(81500)$ & $58.8(200.5)$ & $196.3(669.7)$ \\
7 & $2431(8295)$ & $13764(46961)$ & $31.2(106.4)$ & $74.2(253.2)$ \\
8 & $2821(9626)$ & $14830(50599)$ & $13.4(45.6)$ & $101.9(347.8)$ \\
9 & $2771(9454)$ & $9935(33899)$ & $22.4(76.5)$ & $92.1(314.2)$ \\
10 & $5631(19214)$ & $14356(48981)$ & $36.4(124.2)$ & $123.4(421.1)$ \\
11 & $8146(27795)$ & $12789(43637)$ & $39.5(134.7)$ & $40.5(138.1)$ \\
12 & $3125(10663)$ & $9249(31558)$ & $33.5(114.2)$ & $38.6(131.8)$ \\
\hline
\end{tabular}

\begin{tabular}{|c|c|c|c|c|}
\hline \multicolumn{5}{|c|}{ Table 6. Handbook method input parameters } \\
\hline Facility location & Valencia & Leicester & Atlanta & Stillwater \\
\hline $\begin{array}{l}\text { Average net hourly heat transfer rate to } \\
\text { ground } q_{a}, \mathrm{~W}(\mathrm{Btu} / \mathrm{h})\end{array}$ & $\begin{array}{l}-4.69 \mathrm{E}+02 \\
(-1.60 \mathrm{E}+03)\end{array}$ & $\begin{array}{c}-1.40+04 \\
(-4.77 \mathrm{E}+04)\end{array}$ & $\begin{array}{l}-7.54 \mathrm{E}+03 \\
(-2.57+04)\end{array}$ & $\begin{array}{l}-1.19 \mathrm{E}+03 \\
(-4.06 \mathrm{E}+03)\end{array}$ \\
\hline $\begin{array}{l}\text { Design block cooling/heating load } \\
\qquad q_{l c}, \mathrm{~W}(\mathrm{Btu} / \mathrm{h})\end{array}$ & $\begin{array}{l}-1.70 \mathrm{E}+04 \\
(-5.80 \mathrm{E}+04)\end{array}$ & $\begin{array}{l}-2.80 \mathrm{E}+05 \\
(-9.55 \mathrm{E}+05)\end{array}$ & $\begin{array}{l}-7.50 \mathrm{E}+04 \\
(-2.56 \mathrm{E}+05)\end{array}$ & $\begin{array}{c}-8.90 \mathrm{E}+03 \\
(-3.03 \mathrm{E}+04)\end{array}$ \\
\hline Power at design load $W_{c}, \mathrm{~W}(\mathrm{Btu} / \mathrm{h})$ & --- & --- & --- & --- \\
\hline $\begin{array}{l}\text { Borehole thermal resistance } \\
R_{b}, \mathrm{~m}-\mathrm{K} / \mathrm{W}\left(\mathrm{h}-\mathrm{ft}-{ }^{\circ} \mathrm{F} / \mathrm{Btu}\right)\end{array}$ & $0.110(0.190)$ & $0.064(0.110)$ & $0.069(0.120)$ & $0.162(0.280)$ \\
\hline $\begin{array}{l}\text { Ground thermal resistance for } \\
\text { annual pulse } R_{g a}, \mathrm{~m}-\mathrm{K} / \mathrm{W}\left(\mathrm{h}-\mathrm{ft}-{ }^{\circ} \mathrm{F} / \mathrm{Btu}\right)\end{array}$ & $0.193(0.334)$ & $0.059(0.103)$ & $0.086(0.149)$ & $0.078(0.136)$ \\
\hline $\begin{array}{l}\text { Ground thermal resistance for } \\
\text { monthly pulse } R_{g m}, \mathrm{~m}-\mathrm{K} / \mathrm{W}\left(\mathrm{h}-\mathrm{ft}-{ }^{\circ} \mathrm{F} / \mathrm{Btu}\right)\end{array}$ & $0.244(0.422)$ & $0.119(0.206)$ & $0.117(0.202)$ & $0.153(0.265)$ \\
\hline $\begin{array}{l}\text { Ground thermal resistance for } \\
\left.\text { sub-daily pulse } R_{g d}, \mathrm{~m}-\mathrm{K} / \mathrm{W} \text { (h-ft- }{ }^{\circ} \mathrm{F} / \mathrm{Btu}\right)\end{array}$ & $0.169(0.292)$ & $0.094(0.162)$ & $0.095(0.165)$ & $0.106(0.183)$ \\
\hline $\begin{array}{l}\text { Design month part load factor, } \\
\qquad P L F_{m} \text {, unitless }\end{array}$ & 0.27 & 0.42 & 0.33 & 0.55 \\
\hline Short-circuit heat loss factor & 1.04 & 1.04 & 1.04 & 1.04 \\
\hline
\end{tabular}




\begin{tabular}{|c|c|c|c|c|}
\hline $\begin{array}{l}\text { Undisturbed ground } \\
\text { temperature } t_{g},{ }^{\circ} \mathrm{C}\left({ }^{\circ} \mathrm{F}\right)\end{array}$ & $19.5(67.1)$ & $13.2(55.8)$ & $19.5(67.0)$ & $17.3(63.1)$ \\
\hline $\begin{array}{l}\text { Borehole interference } \\
\text { temperature penalty } t_{p},{ }^{\circ} \mathrm{C}\left({ }^{\circ} \mathrm{F}\right)\end{array}$ & $-0.50(-0.90)$ & $-0.98(-1.76)$ & $-0.37(-0.67)$ & $-0.32(-0.57)$ \\
\hline $\begin{array}{l}\text { Heat pump design inlet } \\
\text { temperature } t_{w i},{ }^{\circ} \mathrm{C}\left({ }^{\circ} \mathrm{F}\right)\end{array}$ & $27.2(81.0)$ & $18.2(64.8)$ & $30.2(86.4)$ & $27.5(81.5)$ \\
\hline $\begin{array}{l}\text { Heat pump design outlet } \\
\text { temperature } t_{w o},{ }^{\circ} \mathrm{C}\left({ }^{\circ} \mathrm{F}\right)\end{array}$ & 32.7 (90.9) & $23.5(74.3)$ & $37.7(99.8)$ & $30.8(87.5)$ \\
\hline
\end{tabular}

\begin{tabular}{|c|cccc|}
\hline \multicolumn{6}{|c|}{ Table 7. Actual and computed design lengths } \\
\hline Borehole Depth, m (ft) & Valencia & Leicester & Atlanta & Stillwater \\
\hline Actual & $50(164)$ & $100(328)$ & $122(400)$ & $75(246)$ \\
Handbook & $101(333)$ & $160(524)$ & $96(314)$ & $101(330)$ \\
Design tool & $52(172)$ & $106(342)$ & $125(409)$ & $76(250)$ \\
\hline
\end{tabular}

\begin{tabular}{|c|cccc|}
\hline \multicolumn{5}{|c|}{ Table 8. Over/undersizing errors for each design method } \\
\hline Over/Undersizing Error & Valencia & Leicester & Atlanta & Stillwater \\
\hline Handbook & $103 \%$ & $60 \%$ & $-21 \%$ & $26 \%$ \\
Design tool & $5 \%$ & $6 \%$ & $2 \%$ & $2 \%$ \\
\hline
\end{tabular}

\begin{tabular}{|c|cccc|}
\hline \multicolumn{5}{|c|}{ Table 9. Borehole thermal resistance inputs } \\
\hline $\begin{array}{c}\text { Borehole Thermal Resistance, } \\
\text { m-K/W (h-ft- }{ }^{\circ} \text { F/Btu) }\end{array}$ & Valencia & Leicester & Atlanta & Stillwater \\
\hline Handbook & $0.110(0.190)$ & $0.0636(0.110)$ & $0.0693(0.120)$ & $0.162(0.280)$ \\
Design Tool & $0.111(0.192)$ & $0.0953(0.165)$ & $0.101(0.175)$ & $0.150(0.180)$ \\
\hline
\end{tabular}

\begin{tabular}{|c|cccc|}
\hline \multicolumn{2}{|c|}{ Table 10. Over/undersizing errors after exploration of differences } \\
\hline Over/Undersizing Error & Valencia & Leicester & Atlanta & Stillwater \\
\hline Handbook & $103 \%$ & $167 \%$ & $-21 \%$ & $76 \%$ \\
Design tool & $5 \%$ & $4 \%$ & $2 \%$ & $2 \%$ \\
Design tool w/ handbook loading & $55 \%$ & $85 \%$ & $-20 \%$ & $53 \%$ \\
Design tool w/ handbook loading and BTR & $58 \%$ & $131 \%$ & $-31 \%$ & $70 \%$ \\
\hline
\end{tabular}

